\title{
Translational effects of robot mediated therapy in subacute stroke patients: an experimental evaluation of upper limb motor recovery
}

Eduardo Palermo Alessandra Pacilli ${ }^{1}$, Serena Filoni ${ }^{3}$

${ }^{1}$ Department of Mechanical and Aerospace Engineering, Sapienza University of Rome, Rome, Italy

2 Seidenberg School of Computer Science and Information Systems, Pace University, New York, NY, United States

3 Fondazione Centri di Riabilitazione Padre Pio Onlus, San Giovanni Rotondo, Italy

4 IRCCS Centro Neurolesi "Bonino-Pulejo", Messina, Italy

Corresponding Author: Eduardo Palermo

Email address: eduardo.palermo@uniroma1.it

Robot-mediated therapies enhance the recovery of post-stroke patients with motor deficits. Repetitive and repeatable exercises are essential for rehabilitation following brain damage or other disorders that impact the central nervous system, as plasticity permits to reorganize its neural structure, fostering motor relearning. Despite so many studies that claim the validity of robot mediated therapy in post-stroke patient rehabilitation, it is still difficult to assess to what extent its adoption improves the efficacy of traditional therapy in daily life, and also because most of the studies involved planar robots. In this paper, we report the effects of a 20-session-rehabilitation project involving the Armeo Power robot, an assistive exoskeleton to perform 3D upper limb movements, in addition to conventional rehabilitation therapy, on 10 subacute stroke survivors. Patients were evaluated through clinical scales and a kinematic assessment of the upper limbs, both pre- and posttreatment. A set of indices based on the patients' 3D kinematic data, gathered from an optoelectronic system, was calculated. Statistical analysis showed a remarkable difference in most parameters between pre- and post-treatment. Significant correlations between the kinematic parameters and clinical scales were found. Our findings suggest that 3D robotmediated rehabilitation, in addition to conventional therapy, could represent an effective means for the recovery of upper limb disability. Kinematic assessment may represent a valid tool for objectively evaluating the efficacy of the rehabilitation treatment. 
1 Translational effects of robot mediated therapy in subacute stroke patients: an experimental evaluation of upper limb motor recovery

Eduardo Palermo ${ }^{1}$, Darren Richard Hayes ${ }^{1,2}$, Emanuele Francesco Russo ${ }^{3}$, Rocco Salvatore Calabrò ${ }^{4}$, Alessandra Pacilli ${ }^{1}$, Serena Filoni ${ }^{3}$

51 Department of Mechanical and Aerospace Engineering, "Sapienza" University Of Rome, Via

6 Eudossiana 18, 00184, Rome, Italy; eduardo.palermo@uniroma1.it;

7 pacillialessandra@gmail.com.

$8 \quad 2$ Seidenberg School of Computer Science and Information Systems, Pace University, One Pace

$9 \quad$ Plaza, New York, NY, United States; dhayes@pace.edu

$10{ }^{3}$ Fondazione Centri di Riabilitazione Padre Pio Onlus, Viale Cappuccini 77, 71013, San Giovanni

11 Rotondo, Italy; emanuele.fr88@gmail.com; serena.diba@gmail.com

$12{ }^{4}$ IRCCS Centro Neurolesi "Bonino-Pulejo", Strada Statale 113, C.da Casazza, 98124, Messina, 13 Messina, Italy; salbro77@tiscali.it. 


\section{Abstract}

15 Robot-mediated therapies enhance the recovery of post-stroke patients with motor deficits.

16 Repetitive and repeatable exercises are essential for rehabilitation following brain damage or

17 other disorders that impact the central nervous system, as plasticity permits to reorganize its

18 neural structure, fostering motor relearning. Despite so many studies that claim the validity of

19 robot mediated therapy in post-stroke patient rehabilitation, it is still difficult to assess to what

20 extent its adoption improves the efficacy of traditional therapy in daily life, and also because

21 most of the studies involved planar robots. In this paper, we report the effects of a 20-session-

22 rehabilitation project involving the Armeo Power robot, an assistive exoskeleton to perform 3D

23 upper limb movements, in addition to conventional rehabilitation therapy, on 10 subacute

24 stroke survivors. Patients were evaluated through clinical scales and a kinematic assessment of

25 the upper limbs, both pre- and post-treatment. A set of indices based on the patients' 3D

26 kinematic data, gathered from an optoelectronic system, was calculated. Statistical analysis

27 showed a remarkable difference in most parameters between pre- and post-treatment.

28 Significant correlations between the kinematic parameters and clinical scales were found. Our

29 findings suggest that 3D robot-mediated rehabilitation, in addition to conventional therapy,

30 could represent an effective means for the recovery of upper limb disability. Kinematic

31 assessment may represent a valid tool for objectively evaluating the efficacy of the 32 rehabilitation treatment. 


\section{Introduction}

Stroke, both ischemic and hemorragic, affects about 10 million people every year worldwide [1], representing the second most frequent cause of death, after coronary artery disease and is the leading cause of disability in the elderly [2]. Many stroke survivors (about 42 million in 2015) [3] sustain neurological damage, which is often permanent. Among other impairments, stroke can compromise use of the upper limbs, thereby negatively impacting common daily living activities - (ADL) [4].

Although stroke patients are usually able to recover their ability to walk independently in a relatively short time, thanks to advanced rehabilitation therapies, a complete recovery of upper limb function is not as common [5]. Hence, effective therapies must be repetitive, targetoriented and intense, in order to stimulate the neural plasticity processes, and are fundamental to the recovery of motor functionality [6]. Traditional therapy, manually administered by rehabilitation operators, rarely meets all of these criteria. The introduction of assisted robot therapy has improved the efficacy of upper limb rehabilitation and significantly improved the living conditions of patients [7].

In recent years, technological advances, and increasing interest in robotic rehabilitation, have led to the development of high performance machines that can provide support to the rehabilitation operator; in some cases, they can even perform a perfectly complementary job [8]. Since the 1990s, these devices have become more pervasive. The first models allowed the operator to utilize pre-set tasks, and were activated "as needed" [9], [10], thereby allowing the rehabilitation operator to follow multiple rehabilitation treatments simultaneously [11]. More recently, robots have integrated rehabilitation strategies that adapt to patient feedback. For example, robots can react to forces applied by the patient during rehabilitation [12].

An essential feature of robotic devices is the ability to perform repetitive movements over a long period of time. The repetition and intensity of exercises are crucial in rehabilitative therapies for patients affected by stroke or other neurological pathologies. Research has shown that neural plasticity is preserved after a brain injury, thereby allowing for new connections to form between the neurons while their gradual reorganization can restore movement and functionality to the affected limb [13]. Thanks to the virtual environments where exercises are 
62 performed, in the form of games with specific goals, the patient is more immersed compared to 63 traditional therapies, which constitutes a further benefit.

64 Noteworthy, examples of upper limb rehabilitation robots currently available on the market or in research laboratories include the MIT-Manus for the end-effector typology [14], [15], and the Armeo ${ }^{\circledR}$ Power exoskeleton (Hocoma, Inc.) [16], which is derived from the research prototype Armin [17], [18]. The latter has been involved in studies that introduced a novel rehabilitation solution to foster neural plasticity, which showed promising results derived from transcranial magnetic stimulation [19].

Rehabilitation mediated by robots also provides quantitative results about improvements in task execution, thereby allowing researchers to quantitatively monitor the recovery of limb functionality [20]. These performance indicators represent a fundamental method to evaluate the administration of specific rehabilitation protocols or the prescription of different exercises during rehabilitation. Performance data used to estimate the patient's motion capabilities can be obtained during specific exercises, via software installed on the device.

Considering this potential, robot mediated therapy (RMT) became prominent in research activities that were focused on improving traditional rehabilitation paradigms [21]. Although many studies to date have reported on the recovery of post-stroke patients treated through RMT, it is still difficult to assess the extent to which these results go beyond traditional therapies administered within a comparable timeframe [22]. In other words, despite the greater level and quality of both support and stimulation provided to patient, and the evaluating tools made available to clinicians, demonstrating higher effectiveness in recovery of RMT with respect to traditional therapy is still an open challenge.

One reason for this lack of evidence lies in the heterogeneity of RMT solutions and, consequently, in the wide variety of strategies that have been proposed to evaluate its effects. To analyse pre-post treatment effects, many studies have combined a kinematic evaluation of patients' motor performance compared to traditional evaluation techniques, in an effort to overcome the intrinsic challenges associated with replicating clinical scales [23]. In fact, despite being designed to comprehensively evaluate different aspects of motor deficit resulting from a stroke, clinical scales are prone to uncommon sensitivity, ceiling effects, and subjectivity in their 
91 administration by the operator [24][25][26]. However, in most cases, this type of 92 supplementary metric is calculated on the same gestures performed for the treatment. 93 Consequently, in order to reveal the translational effects of rehabilitation, an evaluation of the 94 motor performance regained by the patients should involve gestures that mirror daily activities, 95 and are derived from the RMT scenario [27].

96 Several studies have assessed the possibility of using a kinematic evaluation based on a 97 simple daily-life inspired gesture, to objectively assess stroke-related motor impairment. van Kordelaar et al. proposed evaluating kinematic parameters that are based on the hand trajectory recorded by an electromagnetic motion tracking device, during a simple exercise based on reaching and moving objects on a table [28]. A similar paradigm, was proposed by Rohrer et al., that assessed motion smoothness changes during recovery in the aftermath of a stroke, by leveraging a MIT-Manus [25]. However, these movements are planar and the gravity load effect is supported by the robot or by the table. In contrast, a 3-DoF protocol would 104 facilitate an evaluation of the final effect of recovery, where the force exerted for a vertical elevation of the hand plays an important role. Caimmi et al. proposed a 3-DoF protocol where the subject was tasked with reaching towards a target placed in front of him at shoulder level and starting from a lower position. Kinematic indices, based on motion capturing, demonstrated improvements for stroke survivors thanks to constraint-induced movement therapy [29].

In this paper, we adopted a protocol similar to the one introduced in [29], for evaluating

111 the translational effects of an RMT-based rehabilitation project and administrated to ten stroke

112 survivors, using a rehabilitation exoskeleton: the ARMEO Power device. In particular, we 113 primarily sought to investigate whether kinematic indices, based on motion capturing a 3D 114 daily-life inspired gesture, improved after the administration of an RMT protocol, which 115 involved an exoskeleton for 3D upper limb rehabilitation. As a secondary goal, we evaluated 116 how these indices are in agreement with patient assessments that have been evaluated using 117 the most widely-adopted clinical scales for post-stroke motor impairment.

\section{2. Methods}


119

121

123

125

\subsection{Patients' description}

Ten subjects ( 8 males and two females, mean age $60.1 \pm 18.3$ years) affected by stroke in the sub-acute phase ( $4.0 \pm 1.5$ months after the event; 5 with left and 5 with right hemiparesis) were enrolled in the study.

Inclusion criteria were:

- unilateral paresis from a single supratentorial stroke occurring at least six months prior;

- sufficient cognition to follow simple instructions and understand the purpose of the study (Mini-Mental State Examination, MMSE score > 18 points) [8];

- $\quad$ ability to perform the task proposed (pointing a target, with the unaffected and with affected limb);

- $\quad$ ability to remain in a sitting posture.

Exclusion criteria were:

- participation in other studies or rehabilitation programs;

- bilateral impairment;

- $\quad$ severe spasticity (Modified Ashworth Scale score $\geq 3$ );

- severe sensory deficits in the paretic upper limb;

- other neurological, neuromuscular or orthopedic (shoulder sub-luxation or pain in the upper limb) disorders, or visual deficit;

- refusal or inability to provide informed consent;

- other concurrent severe medical problems.

Table 1 reports the primary clinical data of the patients included in the study. Patients were clinically evaluated using the four most adopted rating scales in stroke: the motor subsection of the Functional Independence Measure (FIM) [30], Barthel Index (BI)[31], Frenchay Arm Test (FAT) [32], and Fugl-Meyer Assessment (FMA, Motor function sections, maximum score 66) [33].

\subsection{Treatment protocol and device}

This study was performed in accordance with the Declaration of Helsinki and was 
147 approved by the ethics committees of IRCCS Centro neurolesi Bonino Pulejo (study registration

148 number 43/2013). Informed consent was obtained from all subjects enrolled in this study.

149 Patients underwent a rehabilitation program of 20 sessions, each lasting 50 minutes, five 150 sessions per week, using the Armeo ${ }^{\circledR}$ Power exoskeleton, in addition to a session of 151 conventional rehabilitation therapies conducted with the same duration.

152 The Armeo ${ }^{\circledR}$ Power (Figure 1) is a motorized orthosis for the upper limb with six degrees of 153 freedom (DoFs): three DoFs for the shoulder, one for the elbow flexion, one for the forearm 154 supination, and one for the wrist flexion. Each joint is powered by a motor and equipped with 155 two angle sensors.

156 The device can support the patient's arm weight, thereby providing a feeling of 157 fluctuation, and assists it in a large 3D workspace during execution of the exercises. The 158 presence of a suspension system allows the facilitator to set and adjust the sensitivity of the 159 robot depending on the characteristics of each patient. Arm and forearm lengths are both 160 adjustable, so that the device can be adapted for use by a large selection of patients.

161 The interface used for the execution of exercises, which appear in the form of games, is 162 designed to simulate arm gestures and provide a simple virtual environment. Increasing levels 163 of difficulty can be selected, which in turn determines the speed of the movements, their 164 direction and the work area, depending on the degree of motility of the subject undergoing 165 rehabilitation.

166 Each robotic session, which lasted 50 minutes, consisted of: 10 minutes of passive 167 mobilization for familiarization and to decrease the patient's spasticity, if present; and 40 168 minutes of task-oriented exercises that were calibrated according to the patient's abilities and 169 with increasing difficulty over the course of the training period.

\subsection{Experimental setup for kinematic analysis}

To evaluate the effects of the prescribed treatment, patients underwent a 3D kinematic

172 analysis, both pre- and post-treatment. Patient movements were recorded during a pointing 173 task (Figure 2), using an Optoelectronic System (OS), the BTS SMART-DX 300 [34], which

174 consists of six infrared CCD cameras with a resolution of $650 \times 480$ pixels, and an acquisition rate 175 of $120 \mathrm{~Hz}$. 
In this study, a subset of the kinematic model proposed by G. Rab [35] has been adopted,

177 to ensure the optimal execution of the exercise. In particular, the head, neck and pelvis

178 segments have been removed. Reflective markers were placed on the patient's body,

179 referenced in the model (Figure 3). The wrist joint is modelled as a universal (saddle) joint with

180 two-degrees-of-freedom, where wrist movement occurs in flexion-extension and radio-ulnar

181 deviation; the elbow like a hinge joint with two degrees of freedom; the shoulder as a spherical

182 joint with three degrees of freedom.

183 The pointing task designed for 3D kinematics acquisition required reaching a target, 184 placed on the subject's sagittal plane, at shoulder height, and at a distance from the body equal 185 to the patient's arm length (measured from the acromion marker to the midpoint between the 186 radius and ulna markers). The patient was sitting on a chair with his hands stretched along his

187 hips and his back resting but not locked in that position, thereby allowing compensatory 188 movements, which were also measured (Figure 2).

189 Each of the two kinematic evaluations (pre- and post-treatment) were recorded in a 190 session in which the patient was invited to reach and point at the target from a neutral 191 position, without straining, first with the healthy limb and then with the paretic one. Repeating

192 the task six times took about 10 minutes.

193

194

195

196

197

198

199

200

201

202

203

204

\subsection{Data processing and statistical analysis}

Three-dimensional marker trajectories were recorded using frame-by-frame acquisition software (SMART Capture - BTS, Milan, Italy) and labelled using frame-by-frame tracking software (SMART Tracker - BTS, Milan, Italy). The captured data were transferred to MATLAB software (The Mathwors Inc., Natick, Massachusetts), were interpolated and filtered with a 6 $\mathrm{Hz}$ second-order Butterworth filter in both forward and reverse directions, resulting in a zerophase distortion and fourth order filtering.

The velocity of the hand marker was computed using numerical differentiation. Movement onset was defined at the time when the velocity of the hand marker exceeded $5 \%$ of the maximum velocity in the pointing phase. Movement offset was detected when the velocity of the hand was below the threshold previously described [36].

Kinematic data of the session were processed to calculate the following indices: 
205

206

207

208

209

210

211

212

213

214

215

216

217

218

219

220

221

222

223

224

225

226

227

228

229

230

- Movement time (MT), as the total execution time of the task (between onset and offset), measured in seconds [5], [37]-[39];

- Peak velocity (PV), as the maximum value of the speed profile curve of the hand marker, measured in meters per second [37], [40]-[44];

- Time to PV (TtPV), as the percentage of time from the beginning of the movement to the peak speed [37], [43];

- Normalized Jerk (NJ), as a non-dimensional quantity which corresponds to the square root of the jerk (third derivative of the position of the hand marker with respect to time), mediated over the entire duration of the movement, and normalized with respect to MT and to the total displacement of the onset and offsets (L) [41], [42], [45];

- Trunk Displacement (TD), measured in meters to identify compensation movements, calculated as the difference between the maximum displacement of the trunk marker and its initial position in space, normalized with respect to distance C7-sacrum, expressed as a percentage [37], [40], [41];

- Hand Path Ratio (HPR) is the ratio of the distance travelled by the hand between the movement onset and offset and the straight-line distance between the starting and destination targets, expressed as a percentage [40], [43], [44], [46].

MT, PV, and TtPV indices are related to the time required for pointing at the target and the speed at which the task is performed.

NJ quantifies the fluidity of motion: higher values correspond to lower smoothness, reflecting poor fluidity in motion, or absence of fine tuning of muscular control, whereas a fluid movement will be expressed by a lower value. Although other indices of smoothness have been proven valuable during the last few years [47], today $\mathrm{NJ}$ is the most widely adopted index for smoothness.

TD provides information about the compensation strategies implemented by the patient during execution of the task. 
231

232

233

234

235

236

237

238

239

240

241

242

243

244

245

246

247

248

249

250

251

252

253

254

255

256

257

258

259

HPR, instead is considered an index of motion accuracy in point-to-point movements [48]. Statistical analyses were performed with SPSS software (Statistical Packages for Social Sciences, version 24.0, SPSS Inc., Chicago, IL). Considering the non-normal distribution of the indices and the small size of the sample, non-parametric tests with a 95\% confidence interval ( $\alpha$ $=0.05)$ were applied. In particular, the Wilcoxon signed-rank test 2-tailed was chosen to verify whether there were differences between pre- and post-treatment for each parameter. The Spearman correlation test was performed to highlight any correlation between kinematic parameters and the main clinical scales used.

\section{Results}

An example of reaching trajectories, obtained during the evaluation tasks, is depicted in Figure 4. Figure 5 reports mean and standard deviation values of the $\mathrm{NJ}$ calculated on hand trajectories during each task repetition. Significant differences between pre- and posttreatment kinematic indices were found for $\mathrm{MT}(Z=-2.701, p=0.007), \mathrm{NJ}(Z=-2.701, p=$ 0.007), TD $(Z=-2.701, p=0.007)$, and $\operatorname{HPR}(Z=-2.701, p=0.007)$. The average values of all these parameters were lower after the treatment than before, as reported in Figure 6. No significant difference was found for PV, and TtPv between the pre- and post-treatment evaluations. As displayed in Figure 5 and Figure 6, the values of the indices, derived from the affected arm, are reported along with values obtained from the unaffected arm, to visually compare the difference in the indices and illustrate improvement.

All of the administered clinical assessment scales resulted in pre- vs. post-treatment significant decrease: $\operatorname{FIM}(Z=-2.803, p=0.005), \mathrm{BI}(Z=-2.809, p=0.005)$, FAT $(Z=-2.831, p=$ 0.005), FMA ( $Z=-2.807, p=0.005)$, as reported in Table 2.

Table 3 reports the results of the Spearman correlation test, across all kinematic parameters and all administered clinical assessment scales. A strong tangentially significant correlation was found between FAT and HPR. A moderate, yet insignificant, correlation $(0.40<$ $|r s|<0.59)$, was found between BI and MT, BI and TD, FAT and TtPV, and FMA and HPR.

\section{Discussion}


In this study, we analysed the effects of robot mediated therapy conducted with an exoskeleton that supported the 3D movement of the upper limbs, involved ten stroke survivors, using a pre- vs. post-treatment 3D kinematic analysis of a specific upper limb gesture, which mirrored a daily living activity. Their residual motion capabilities were evaluated by means of a set of kinematic parameters that were measured during execution of a reaching task with both the paretic and the unaffected arm, other than by using the four most adopted clinical scales.

Our findings demonstrate the benefits of a rehabilitation program focused on the range of motion capabilities of post-stroke patients. Indeed, these patients demonstrated an improvement across all administered clinical scales, and these results are in agreement with the kinematic analysis conducted. The trajectories of reaching tasks performed after treatment were smoother and more accurate. Four out of the six kinematic indices computed on the reaching trajectories travelled after the treatment of the paretic arm were different to those obtained before the treatment. In particular, indices obtained with the paretic arm, after the treatment, showed movement more comparable to the unaffected arm.

The significant decrease in MT indicates regained mobility with gesture performance. A reduced time to complete the task implies a more effective combination of motion smoothness and accuracy. Regardless of the actual distribution of improvement from these two aspects, the overall ability to complete the task in a reduced timeframe indicates an increase in patient independence in daily life, which is a key concern in rehabilitation. Frisoli et al. [38] demonstrated a significant correlation with the total time for the reaching movement with the clinical evaluation of motor impairment in both ischemic and hemorrhagic stroke patients. This index showed a significant decrease after a rehabilitation program, towards the value observed in healthy control group.

$\mathrm{NJ}$ is generally understood as an index of motion smoothness, where higher levels of this parameter are typical of less smoothly controlled gestures [49]. All of the patients showed a noticeable decrease in the NJ average value in reaching tasks performed with the paretic arm. Values of NJ obtained after the RMT program, are closer to those performed with the unaffected arm. 
289 the shortest possible distance between the start and target points. A line connecting the two 290 points does not exactly represent the path chosen by unimpaired subjects, as shown in Figure

291 3. However, the difference between the actual hand trajectory and the line is an important 292 parameter in evaluating accuracy in reaching tasks [39]. Stroke survivors who participated in 293 our study exhibited a significant decrease in this index in post-treatment trials compared to pre294 treatment ones, with an average value more comparable with that of the unaffected arm.

295 Another significant improvement was observed in the TD index for our sample study. This 296 result can be interpreted as a secondary effect of the restoration of motor activation paths 297 from the motor cortex to muscles. The increased capability of the subject to fire the necessary 298 motor units required less compensatory trunk muscle activity to complete the task [50]. 299 Murphy et al., demonstrated that TD is significantly higher in post-stoke patients than in 300 healthy subjects, and a noteable increase in this index can also be observed between patients 301 with moderate stroke with respect to those with a mild stroke.

302 Interestingly, no significant effect was observed in PV and TtPV. Although these are 303 generally considered indices of motor capability in point-to-point tasks [37], the patients 304 involved in this study did not exhibit any significant variation in these two indices. The restored 305 motor control, highlighted by other observed markers, both clinical and kinematic, was not 306 reflected in the velocity profile of the hand during specific pointing tasks. Thus, our preliminary 307 findings suggests that one should not simply rely on these two indices as effective 308 measurements for the effectiveness of a rehabilitation program.

309 Although the results were obtained from a small patient sample, the findings of the 310 present study are particularly important to current discussions about robot mediated therapy. 311 Moreover, to date, several studies have assessed improvements in the motion capabilities of 312 stroke survivors after RMT treatments, for a larger cohort of subjects [51]. However, 313 improvement has mainly been evaluated by means of clinical rating scales or kinematic indices 314 computed on gesture trajectories performed during rehabilitation treatment. Thus, it is 315 generally accepted that training stroke survivors to perform specific upper arm trajectories, in a

316 controlled and assisted manner that is facilitated by a robotic device, leads to improvement in 317 performing a specific task. However, a key issue with motor rehabilitation is the translational 
318 effect of therapy, i.e. the potential to improve gestures typically associated with daily life,

319 distinct from those performed in a rehabilitation program [52]. This problem is of great

320 importance in analysing the robot mediated therapy effect throughout the entire rehabilitation

321 process. Current studies only merely use the robotic device as as a theraputic instrument, while

322 the kinematic evaluation was used to evaluate a simple gesture, which was highly

323 representative of a daily life scenario.

324 Despite the number of RMT studies conducted thus far, proving increased performance

325 compared to a traditional rehabilitation program, within the same timeframe, remains a

326 challenge [22]. One reason is the lack of a standardized evaluation protocol for measuring the

327 impact, apart from the use of clinical scales. Although highly comprehensive and well

328 structured, clinical scales are not an objective tool, and are often comprised of different

329 characteristics related to disability, ranging from motor capabilities to facial expressions or

330 psychological treats. The protocol presented in this study has the potential to serve as a

331 standard evaluation tool for more objectively quantifying upper limb motor smoothness and

332 accuracy, derived from a rehabilitation program, and ultimately inspiring comparative studies

333 on the efficacy of RMT versus traditional therapy. Several studies have examined the pointing

334 movement in stroke patients [37], [38], [40], [53]-[55], however they have used different

335 kinematic variables to analyse the movement, despite the common goal of being able to

336 quantify speed, accuracy and fluidity of movement. In this vein, a comparative analysis of

337 patient behaviour in kinematic evaluation, in terms of clinical scales score, is of great 338 importance.

339 The kinematic evaluation protocol that we adopted, instead, was introduced by Caimmi et

340 al [56], to evaluate the effects of constraint-induced therapy. In this study, we used this method

341 to evaluate effects of RMT sessions, performed using a rehabilitation exoskeleton that induces

342 3D movements of the upper limb. Reporting these findings is valuable as the literature is lacking

343 when it comes to these types of studies, especially with RMT solutions inducing planar

344 movements, where the gravity effect is completely supported. The adoption of 3D robotics,

345 assisting the subjects in compensating for gravity, is expected to enhance this capability.

346 To consolidate the preliminary findings of this study, and positively contribute to the 
347 current discussions about the impact of RMT, future studies should involve a larger patient

348 sample, in parallel with a control group undergoing conventional therapy. If confirmed on a

349 larger number of patients, the positive results reported herein will pave the way for the

350 establishment of a standardized procedure for objectively evaluating motor recovery in

351 conjunction with a robotic rehabilitation program. This tool would have a tremendous potential

352 in facilitating comparative studies about the effects of RMT compared to traditional physical

353 therapy for rehabilitation.

354 Moreover, apart from the advantaged documented in this paper, as in other similar

355 studies, it is not possible to isolate the effects of RMT per se. A physiological progressive

356 improvement in the motor capabilities of stroke survivors, during the subacute phase, has

357 already been demonstrated [27]. Thus, a comparative study with only two groups of stroke

358 survivors would be required, where one group is treated with RMT, which would accurately

359 quantify the benefits of RMT, although this would be questionable in terms of ethics.

360 Ultimately, reporting the results of a specific therapy, using a standard protocol and a set of

361 accepted indices, is valuable, as it permits a better interpretation of the actual outcomes of the

362 therapy.

363

364

365

366

367

368

369

370

371

372

373

374

375

\section{Conclusions}

In this study, we analysed the effects of robot-mediated therapy on ten stroke survivors, through a pre- vs. post-treatment 3D kinematic analysis of a specific upper limb gesture, simulating daily living activities. Their residual motion capabilities were evaluated by means of a set of kinematic parameters measured during the execution of a reaching task with both a paretic and an unaffected arm.

Our results highlighted the efficacy of a rehabilitation program that benefits the motion capabilities of patients. Patients exhibited improvements in all of the administered clinical scales, which was in agreement with the kinematic analysis conducted.

Although the analysis was obtained from a small sample of patients, the findings of our study have the potential to contribute to the current discussions about robot-mediated therapy. The protocol presented in this study, inspired by daily-life gestures (upper limb motor tasks), may represent a step forward in establishing a standard evaluation procedure, for the 
376

377

378

379

380

381

382

383

384

385

386

387

388

389

390

391

392

393

394

395

396

397

398

399

400

401

402

403

404

405

406

407

408

409

410

411

412

413

414

415

416

417

418

objective quantification of upper limb motor recovery following RMT-based treatments.

\section{References}

[1] T. Vos, R. M. Barber, B. Bell, A. Bertozzi-Villa, S. Biryukov, I. Bolliger, F. Charlson, A. Davis, L. Degenhardt, D. Dicker, L. Duan, H. Erskine, V. L. Feigin, A. J. Ferrari, C. Fitzmaurice, T. Fleming, N. Graetz, C. Guinovart, J. Haagsma, G. M. Hansen, S. W. Hanson, K. R. Heuton, H. Higashi, N. Kassebaum, H. Kyu, E. Laurie, X. Liang, K. Lofgren, R. Lozano, M. F. MacIntyre, M. Moradi-Lakeh, M. Naghavi, G. Nguyen, S. Odell, K. Ortblad, D. A. Roberts, G. A. Roth, L. Sandar, P. T. Serina, J. D. Stanaway, C. Steiner, B. Thomas, S. E. Vollset, H. Whiteford, T. M. Wolock, P. Ye, M. Zhou, M. A. Ãvila, G. M. Aasvang, C. Abbafati, A. A. Ozgoren, F. Abd-Allah, M. I. A. Aziz, S. F. Abera, V. Aboyans, J. P. Abraham, B. Abraham, I. Abubakar, L. J. Abu-Raddad, N. M. Abu-Rmeileh, T. C. Aburto, T. Achoki, I. N. Ackerman, A. Adelekan, Z. Ademi, A. K. Adou, J. C. Adsuar, J. Arnlov, E. E. Agardh, M. J. Al Khabouri, S. S. Alam, D. Alasfoor, M. I. Albittar, M. A. Alegretti, A. V Aleman, Z. A. Alemu, R. Alfonso-Cristancho, S. Alhabib, R. Ali, F. Alla, P. Allebeck, P. J. Allen, M. A. AlMazroa, U. Alsharif, E. Alvarez, N. Alvis-Guzman, O. Ameli, H. Amini, W. Ammar, B. O. Anderson, H. R. Anderson, C. A. T. Antonio, P. Anwari, H. Apfel, V. S. A. Arsenijevic, A. Artaman, R. J. Asghar, R. Assadi, L. S. Atkins, C. Atkinson, A. Badawi, M. C. Bahit, T. Bakfalouni, K. Balakrishnan, S. Balalla, A. Banerjee, S. L. Barker-Collo, S. Barquera, L. Barregard, L. H. Barrero, S. Basu, A. Basu, A. Baxter, J. Beardsley, N. Bedi, E. Beghi, T. Bekele, M. L. Bell, C. Benjet, D. A. Bennett, I. M. Bensenor, H. Benzian, E. Bernabe, T. J. Beyene, N. Bhala, A. Bhalla, Z. Bhutta, K. Bienhoff, B. Bikbov, A. Bin Abdulhak, J. D. Blore, F. M. Blyth, M. A. Bohensky, B. B. Basara, G. Borges, N. M. Bornstein, D. Bose, S. Boufous, R. R. Bourne, L. N. Boyers, M. Brainin, M. Brauer, C. E. Brayne, A. Brazinova, N. J. Breitborde, H. Brenner, A. D. Briggs, P. M. Brooks, J. Brown, T. S. Brugha, R. Buchbinder, G. C. Buckle, G. Bukhman, A. G. Bulloch, M. Burch, R. Burnett, R. Cardenas, N. L. Cabral, I. R. C. Nonato, J. C. Campuzano, J. R. Carapetis, D. O. Carpenter, V. Caso, C. A. Castaneda-Orjuela, F. Catala-Lopez, V. K. Chadha, J.-C. Chang, H. Chen, W. Chen, P. P. Chiang, O. Chimed-Ochir, R. Chowdhury, H. Christensen, C. A. Christophi, S. S. Chugh, M. Cirillo, M. Coggeshall, A. Cohen, V. Colistro, S. M. Colquhoun, A. G. Contreras, L. T. Cooper, C. Cooper, K. Cooperrider, J. Coresh, M. Cortinovis, M. H. Criqui, J. A. Crump, L. Cuevas-Nasu, R. Dandona, L. Dandona, E. Dansereau, H. G. Dantes, P. I. Dargan, G. Davey, D. V Davitoiu, A. Dayama, V. De la Cruz-Gongora, S. F. de la Vega, D. De Leo, B. del Pozo-Cruz, R. P. Dellavalle, K. Deribe, S. Derrett, D. C. Des Jarlais, M. Dessalegn, G. A. deVeber, S. D. Dharmaratne, C. Diaz-Torne, E. L. Ding, K. Dokova, E. R. Dorsey, T. R. Driscoll, H. Duber, A. M. Durrani, K. M. Edmond, R. G. Ellenbogen, M. Endres, S. P. Ermakov, B. Eshrati, A. Esteghamati, K. Estep, S. Fahimi, F. Farzadfar, D. F. Fay, D. T. Felson, S.-M. Fereshtehnejad, J. G. Fernandes, C. P. Ferri, A. Flaxman, N. Foigt, K. J. Foreman, F. G. R. Fowkes, R. C. Franklin, T. Furst, N. D. Futran, B. J. Gabbe, F. G. Gankpe, F. A. GarciaGuerra, J. M. Geleijnse, B. D. Gessner, K. B. Gibney, R. F. Gillum, I. A. Ginawi, M. Giroud, G. Giussani, S. Goenka, K. Goginashvili, P. Gona, T. G. de Cosio, R. A. Gosselin, C. C. Gotay, A. Goto, H. N. Gouda, R. I Guerrant, H. C. Gugnani, D. Gunnell, R. Gupta, R. Gupta, R. A. Gutierrez, N. Hafezi-Nejad, H. Hagan, Y. Halasa, R. R. Hamadeh, H. Hamavid, M. Hammami, G. J. Hankey, Y. Hao, H. L. Harb, J. M. Haro, R. Havmoeller, R. J. Hay, S. Hay, M. 
419

420

421

422

423

424

425

426

427

428

429

430

431

432

433

434

435

436

437

438

439

440

441

442

443

444

445

446

447

448

449

450

451

452

453

454

455

456

457

458

459

460

461

462

T. Hedayati, I. B. H. Pi, P. Heydarpour, M. Hijar, H. W. Hoek, H. J. Hoffman, J. C. Hornberger, H. D. Hosgood, M. Hossain, P. J. Hotez, D. G. Hoy, M. Hsairi, H. Hu, G. Hu, J. J. Huang, C. Huang, L. Huiart, A. Husseini, M. lannarone, K. M. Iburg, K. Innos, M. Inoue, K. H. Jacobsen, S. K. Jassal, P. Jeemon, P. N. Jensen, V. Jha, G. Jiang, Y. Jiang, J. B. Jonas, J. Joseph, K. Juel, H. Kan, A. Karch, C. Karimkhani, G. Karthikeyan, R. Katz, A. Kaul, N. Kawakami, D. S. Kazi, A. H. Kemp, A. P. Kengne, Y. S. Khader, S. E. A. Khalifa, E. A. Khan, G. Khan, Y.-H. Khang, I. Khonelidze, C. Kieling, D. Kim, S. Kim, R. W. Kimokoti, Y. Kinfu, J. M. Kinge, B. M. Kissela, M. Kivipelto, L. Knibbs, A. K. Knudsen, Y. Kokubo, S. Kosen, A. Kramer, M. Kravchenko, R. V Krishnamurthi, S. Krishnaswami, B. K. Defo, B. K. Bicer, E. J. Kuipers, V. S. Kulkarni, K. Kumar, G. A. Kumar, G. F. Kwan, T. Lai, R. Lalloo, H. Lam, Q. Lan, V. C. Lansingh, H. Larson, A. Larsson, A. E. Lawrynowicz, J. L. Leasher, J.-T. Lee, J. Leigh, R. Leung, M. Levi, B. Li, Y. Li, Y. Li, J. liang, S. Lim, H.-H. Lin, M. Lind, M. P. Lindsay, S. E. Lipshultz, S. Liu, B. K. Lloyd, S. L. Ohno, G. Logroscino, K. J. Looker, A. D. Lopez, N. LopezOlmedo, J. Lortet-Tieulent, P. A. Lotufo, N. Low, R. M. Lucas, R. Lunevicius, R. A. Lyons, J. Ma, S. Ma, M. T. Mackay, M. Majdan, R. Malekzadeh, C. C. Mapoma, W. Marcenes, L. M. March, C. Margono, G. B. Marks, M. B. Marzan, J. R. Masci, A. J. Mason-Jones, R. G. Matzopoulos, B. M. Mayosi, T. T. Mazorodze, N. W. McGill, J. J. McGrath, M. McKee, A. McLain, B. J. McMahon, P. A. Meaney, M. M. Mehndiratta, F. Mejia-Rodriguez, W. Mekonnen, Y. A. Melaku, M. Meltzer, Z. A. Memish, G. Mensah, A. Meretoja, F. A. Mhimbira, R. Micha, T. R. Miller, E. J. Mills, P. B. Mitchell, C. N. Mock, T. E. Moffitt, N. M. Ibrahim, K. A. Mohammad, A. H. Mokdad, G. L. Mola, L. Monasta, M. Montico, T. J. Montine, A. R. Moore, A. E. Moran, L. Morawska, R. Mori, J. Moschandreas, W. N. Moturi, M. Moyer, D. Mozaffarian, U. O. Mueller, M. Mukaigawara, M. E. Murdoch, J. Murray, K. S. Murthy, P. Naghavi, Z. Nahas, A. Naheed, K. S. Naidoo, L. Naldi, D. Nand, V. Nangia, K. M. V. Narayan, D. Nash, C. Nejjari, S. P. Neupane, L. M. Newman, C. R. Newton, M. Ng, F. N. Ngalesoni, N. T. Nhung, M. I. Nisar, S. Nolte, O. F. Norheim, R. E. Norman, B. Norrving, L. Nyakarahuka, I. H. Oh, T. Ohkubo, S. B. Omer, J. N. Opio, A. Ortiz, J. D. Pandian, C. I. A. Panelo, C. Papachristou, E.-K. Park, C. D. Parry, A. J. P. Caicedo, S. B. Patten, V. K. Paul, B. I. Pavlin, N. Pearce, L. S. Pedraza, C. A. Pellegrini, D. M. Pereira, F. P. Perez-Ruiz, N. Perico, A. Pervaiz, K. Pesudovs, C. B. Peterson, M. Petzold, M. R. Phillips, D. Phillips, B. Phillips, F. B. Piel, D. Plass, D. Poenaru, G. V Polanczyk, S. Polinder, C. A. Pope, S. Popova, R. G. Poulton, F. Pourmalek, D. Prabhakaran, N. M. Prasad, D. Qato, D. A. Quistberg, A. Rafay, K. Rahimi, V. Rahimi-Movaghar, S. ur Rahman, M. Raju, I. Rakovac, S. M. Rana, H. Razavi, A. Refaat, J. Rehm, G. Remuzzi, S. Resnikoff, A. L. Ribeiro, P. M. Riccio, L. Richardson, J. H. Richardus, A. M. Riederer, M. Robinson, A. Roca, A. Rodriguez, D. Rojas-Rueda, L. Ronfani, D. Rothenbacher, N. Roy, G. M. Ruhago, N. Sabin, R. L. Sacco, K. Ksoreide, S. Saha, R. Sahathevan, M. A. Sahraian, U. Sampson, J. R. Sanabria, L. SanchezRiera, I. S. Santos, M. Satpathy, J. E. Saunders, M. Sawhney, M. I. Saylan, P. Scarborough, B. Schoettker, I. J. Schneider, D. C. Schwebel, J. G. Scott, S. Seedat, S. G. Sepanlou, B. Serdar, E. E. Servan-Mori, K. Shackelford, A. Shaheen, S. Shahraz, T. S. Levy, S. Shangguan, J. She, S. Sheikhbahaei, D. S. Shepard, P. Shi, K. Shibuya, Y. Shinohara, R. Shiri, K. Shishani, I. Shiue, M. G. Shrime, I. D. Sigfusdottir, D. H. Silberberg, E. P. Simard, S. Sindi, J. A. Singh, L. Singh, V. Skirbekk, K. Sliwa, M. Soljak, S. Soneji, S. S. Soshnikov, P. Speyer, L. A. Sposato, C. T. Sreeramareddy, H. Stoeckl, V. K. Stathopoulou, N. Steckling, 
463

464

465

466

467

468

469

470

471

472

473

474

475

476

477

478

479

480

481

482 [2]

483

484

485

486

487

488

489

490

491

492

493

494

495

496

497

498

499

500

501

502

503

504

505

M. B. Stein, D. J. Stein, T. J. Steiner, A. Stewart, E. Stork, L. J. Stovner, K. Stroumpoulis, L. Sturua, B. F. Sunguya, M. Swaroop, B. L. Sykes, K. M. Tabb, K. Takahashi, F. Tan, N. Tandon, D. Tanne, M. Tanner, M. Tavakkoli, H. R. Taylor, B. J. Te Ao, A. M. Temesgen, M. Ten Have, E. Y. Tenkorang, A. S. Terkawi, A. M. Theadom, E. Thomas, A. L. Thorne-Lyman, A. G. Thrift, I. M. Tleyjeh, M. Tonelli, F. Topouzis, J. A. Towbin, H. Toyoshima, J. Traebert, B. X. Tran, L. Trasande, M. Trillini, T. Truelsen, U. Trujillo, M. Tsilimbaris, E. M. Tuzcu, K. N. Ukwaja, E. A. Undurraga, S. B. Uzun, W. H. van Brakel, S. van de Vijver, R. Van Dingenen, C. H. van Gool, Y. Y. Varakin, T. J. Vasankari, M. S. Vavilala, L. J. Veerman, G. VelasquezMelendez, N. Venketasubramanian, L. Vijayakumar, S. Villalpando, F. S. Violante, V. V Vlassov, S. Waller, M. T. Wallin, X. Wan, L. Wang, J. Wang, Y. Wang, T. S. Warouw, S. Weichenthal, E. Weiderpass, R. G. Weintraub, A. Werdecker, K. R. R. Wessells, R. Westerman, J. D. Wilkinson, H. C. Williams, T. N. Williams, S. M. Woldeyohannes, C. DA Wolfe, J. Q. Wong, H. Wong, A. D. Woolf, J. L. Wright, B. Wurtz, G. Xu, G. Yang, Y. Yano, M. A. Yenesew, G. K. Yentur, P. Yip, N. Yonemoto, S.-J. Yoon, M. Younis, C. Yu, K. Y. Kim, M. E. S. Zaki, Y. Zhang, Z. Zhao, Y. Zhao, J. Zhu, D. Zonies, J. R. Zunt, J. A. Salomon, and C. J. Murray, "Global, regional, and national incidence, prevalence, and years lived with disability for 301 acute and chronic diseases and injuries in 188 countries, 1990-2013: a systematic analysis for the Global Burden of Disease Study 2013," Lancet, vol. 386, no. 9995, pp. 743-800, Aug. 2015.

2] H. Wang, M. Naghavi, C. Allen, R. M. Barber, Z. A. Bhutta, A. Carter, D. C. Casey, F. J. Charlson, A. Z. Chen, M. M. Coates, M. Coggeshall, L. Dandona, D. J. Dicker, H. E. Erskine, A. J. Ferrari, C. Fitzmaurice, K. Foreman, M. H. Forouzanfar, M. S. Fraser, N. Fullman, P. W. Gething, E. M. Goldberg, N. Graetz, J. A. Haagsma, S. I. Hay, C. Huynh, C. O. Johnson, N. J. Kassebaum, Y. Kinfu, X. R. Kulikoff, M. Kutz, H. H. Kyu, H. J. Larson, J. Leung, X. Liang, S. S. Lim, M. Lind, R. Lozano, N. Marquez, G. A. Mensah, J. Mikesell, A. H. Mokdad, M. D. Mooney, G. Nguyen, E. Nsoesie, D. M. Pigott, C. Pinho, G. A. Roth, J. A. Salomon, L. Sandar, N. Silpakit, A. Sligar, R. J. D. Sorensen, J. Stanaway, C. Steiner, S. Teeple, B. A. Thomas, C. Troeger, A. VanderZanden, S. E. Vollset, V. Wanga, H. A. Whiteford, T. Wolock, L. Zoeckler, K. H. Abate, C. Abbafati, K. M. Abbas, F. Abd-Allah, S. F. Abera, D. M. X. Abreu, L. J. Abu-Raddad, G. Y. Abyu, T. Achoki, A. L. Adelekan, Z. Ademi, A. K. Adou, J. C. Adsuar, K. A. Afanvi, A. Afshin, E. E. Agardh, A. Agarwal, A. Agrawal, A. A. Kiadaliri, O. N. Ajala, A. S. Akanda, R. O. Akinyemi, T. F. Akinyemiju, N. Akseer, F. H. Al Lami, S. Alabed, Z. Al-Aly, K. Alam, N. K. M. Alam, D. Alasfoor, S. F. Aldhahri, R. W. Aldridge, M. A. Alegretti, A. V Aleman, Z. A. Alemu, L. T. Alexander, S. Alhabib, R. Ali, A. Alkerwi, F. Alla, P. Allebeck, R. Al-Raddadi, U. Alsharif, K. A. Altirkawi, E. A. Martin, N. Alvis-Guzman, A. T. Amare, A. K. Amegah, E. A. Ameh, H. Amini, W. Ammar, S. M. Amrock, H. H. Andersen, B. O. Anderson, G. M. Anderson, C. A. T. Antonio, A. F. Aregay, J. Ärnlöv, V. S. A. Arsenijevic, A. Artaman, H. Asayesh, R. J. Asghar, S. Atique, E. F. G. A. Avokpaho, A. Awasthi, P. Azzopardi, U. Bacha, A. Badawi, M. C. Bahit, K. Balakrishnan, A. Banerjee, A. Barac, S. L. Barker-Collo, T. Bärnighausen, L. Barregard, L. H. Barrero, A. Basu, S. Basu, Y. T. Bayou, S. Bazargan-Hejazi, J. Beardsley, N. Bedi, E. Beghi, H. A. Belay, B. Bell, M. L. Bell, A. K. Bello, D. A. Bennett, I. M. Bensenor, A. Berhane, E. Bernabé, B. D. Betsu, A. S. Beyene, N. Bhala, A. Bhalla, S. Biadgilign, B. Bikbov, A. A. Bin Abdulhak, B. J. Biroscak, S. Biryukov, E. 
506

507

508

509

510

511

512

513

514

515

516

517

518

519

520

521

522

523

524

525

526

527

528

529

530

531

532

533

534

535

536

537

538

539

540

541

542

543

544

545

546

547

548

549
Bjertness, J. D. Blore, C. D. Blosser, M. A. Bohensky, R. Borschmann, D. Bose, R. R. A. Bourne, M. Brainin, C. E. G. Brayne, A. Brazinova, N. J. K. Breitborde, H. Brenner, J. D. Brewer, A. Brown, J. Brown, T. S. Brugha, G. C. Buckle, Z. A. Butt, B. Calabria, I. R. Campos-Nonato, J. C. Campuzano, J. R. Carapetis, R. Cárdenas, D. O. Carpenter, J. J. Carrero, C. A. Castañeda-Orjuela, J. C. Rivas, F. Catalá-López, F. Cavalleri, K. Cercy, J. Cerda, W. Chen, A. Chew, P. P.-C. Chiang, M. Chibalabala, C. E. Chibueze, O. ChimedOchir, V. H. Chisumpa, J.-Y. J. Choi, R. Chowdhury, H. Christensen, D. J. Christopher, L. G. Ciobanu, M. Cirillo, A. J. Cohen, V. Colistro, M. Colomar, S. M. Colquhoun, C. Cooper, L. T. Cooper, M. Cortinovis, B. C. Cowie, J. A. Crump, J. Damsere-Derry, H. Danawi, R. Dandona, F. Daoud, S. C. Darby, P. I. Dargan, J. das Neves, G. Davey, A. C. Davis, D. V Davitoiu, E. F. de Castro, P. de Jager, D. De Leo, L. Degenhardt, R. P. Dellavalle, K. Deribe, A. Deribew, S. D. Dharmaratne, P. K. Dhillon, C. Diaz-Torné, E. L. Ding, K. P. B. dos Santos, E. Dossou, T. R. Driscoll, L. Duan, M. Dubey, B. B. Duncan, R. G. Ellenbogen, C. L. Ellingsen, I. Elyazar, A. Y. Endries, S. P. Ermakov, B. Eshrati, A. Esteghamati, K. Estep, I. D. A. Faghmous, S. Fahimi, E. J. A. Faraon, T. A. Farid, C. S. e S. Farinha, A. Faro, M. S. Farvid, F. Farzadfar, V. L. Feigin, S.-M. Fereshtehnejad, J. G. Fernandes, J. C. Fernandes, F. Fischer, J. R. A. Fitchett, A. Flaxman, N. Foigt, F. G. R. Fowkes, E. B. Franca, R. C. Franklin, J. Friedman, J. Frostad, T. Fürst, N. D. Futran, S. L. Gall, K. Gambashidze, A. Gamkrelidze, P. Ganguly, F. G. Gankpé, T. Gebre, T. T. Gebrehiwot, A. T. Gebremedhin, A. A. Gebru, J. M. Geleijnse, B. D. Gessner, A. G. Ghoshal, K. B. Gibney, R. F. Gillum, S. Gilmour, A. Z. Giref, M. Giroud, M. D. Gishu, G. Giussani, E. Glaser, W. W. Godwin, H. Gomez-Dantes, P. Gona, A. Goodridge, S. V. Gopalani, R. A. Gosselin, C. C. Gotay, A. Goto, H. N. Gouda, F. Greaves, H. C. Gugnani, R. Gupta, R. Gupta, V. Gupta, R. A. Gutiérrez, N. Hafezi-Nejad, D. Haile, A. D. Hailu, G. B. Hailu, Y. A. Halasa, R. R. Hamadeh, S. Hamidi, J. Hancock, A. J. Handal, G. J. Hankey, Y. Hao, H. L. Harb, S. Harikrishnan, J. M. Haro, R. Havmoeller, S. R. Heckbert, I. B. Heredia-Pi, P. Heydarpour, H. B. M. Hilderink, H. W. Hoek, R. S. Hogg, M. Horino, N. Horita, H. D. Hosgood, P. J. Hotez, D. G. Hoy, M. Hsairi, A. S. Htet, M. M. T. Htike, G. Hu, C. Huang, H. Huang, L. Huiart, A. Husseini, I. Huybrechts, G. Huynh, K. M. Iburg, K. Innos, M. Inoue, V. J. Iyer, T. A. Jacobs, K. H. Jacobsen, N. Jahanmehr, M. B. Jakovljevic, P. James, M. Javanbakht, S. P. Jayaraman, A. U. Jayatilleke, P. Jeemon, P. N. Jensen, V. Jha, G. Jiang, Y. Jiang, T. Jibat, A. Jimenez-Corona, J. B. Jonas, T. K. Joshi, Z. Kabir, R. Kamal, H. Kan, S. Kant, A. Karch, C. K. Karema, C. Karimkhani, D. Karletsos, G. Karthikeyan, A. Kasaeian, M. Katibeh, A. Kaul, N. Kawakami, J. F. Kayibanda, P. N. Keiyoro, L. Kemmer, A. H. Kemp, A. P. Kengne, A. Keren, M. Kereselidze, C. N. Kesavachandran, Y. S. Khader, I. A. Khalil, A. R. Khan, E. A. Khan, Y.-H. Khang, S. Khera, T. A. M. Khoja, C. Kieling, D. Kim, Y. J. Kim, B. M. Kissela, N. Kissoon, L. D. Knibbs, A. K. Knudsen, Y. Kokubo, D. Kolte, J. A. Kopec, S. Kosen, P. A. Koul, A. Koyanagi, N. H. Krog, B. K. Defo, B. K. Bicer, A. A. Kudom, E. J. Kuipers, V. S. Kulkarni, G. A. Kumar, G. F. Kwan, A. Lal, D. K. Lal, R. Lalloo, T. Lallukka, H. Lam, J. O. Lam, S. M. Langan, V. C. Lansingh, A. Larsson, D. O. Laryea, A. A. Latif, A. E. B. Lawrynowicz, J. Leigh, M. Levi, Y. Li, M. P. Lindsay, S. E. Lipshultz, P. Y. Liu, S. Liu, Y. Liu, L.T. Lo, G. Logroscino, P. A. Lotufo, R. M. Lucas, R. Lunevicius, R. A. Lyons, S. Ma, V. M. P. Machado, M. T. Mackay, J. H. MacLachlan, H. M. A. El Razek, M. Magdy, A. El Razek, M. Majdan, A. Majeed, R. Malekzadeh, W. A. A. Manamo, J. Mandisarisa, S. Mangalam, C. C. Mapoma, W. Marcenes, D. J. Margolis, G. R. Martin, J. Martinez-Raga, M. B. Marzan, F. 
550

551

552

553

554

555

556

557

558

559

560

561

562

563

564

565

566

567

568

569

570

571

572

573

574

575

576

577

578

579

580

581

582

583

584

585

586

587

588

589

590

591

592

593

Masiye, A. J. Mason-Jones, J. Massano, R. Matzopoulos, B. M. Mayosi, S. T. McGarvey, J. J. McGrath, M. McKee, B. J. McMahon, P. A. Meaney, A. Mehari, M. M. Mehndiratta, F. Mejia-Rodriguez, A. B. Mekonnen, Y. A. Melaku, P. Memiah, Z. A. Memish, W. Mendoza, A. Meretoja, T. J. Meretoja, F. A. Mhimbira, R. Micha, A. Millear, T. R. Miller, M. Mirarefin, A. Misganaw, C. N. Mock, K. A. Mohammad, A. Mohammadi, S. Mohammed, V. Mohan, G. L. D. Mola, L. Monasta, J. C. M. Hernandez, P. Montero, M. Montico, T. J. Montine, M. Moradi-Lakeh, L. Morawska, K. Morgan, R. Mori, D. Mozaffarian, U. O. Mueller, G. V. S. Murthy, S. Murthy, K. I. Musa, J. B. Nachega, G. Nagel, K. S. Naidoo, N. Naik, L. Naldi, V. Nangia, D. Nash, C. Nejjari, S. Neupane, C. R. Newton, J. N. Newton, M. Ng, F. N. Ngalesoni, J. de Dieu Ngirabega, Q. Le Nguyen, M. I. Nisar, P. M. N. Pete, M. Nomura, O. F. Norheim, P. E. Norman, B. Norrving, L. Nyakarahuka, F. A. Ogbo, T. Ohkubo, F. A. Ojelabi, P. R. Olivares, B. O. Olusanya, J. O. Olusanya, J. N. Opio, E. Oren, A. Ortiz, M. Osman, E. Ota, R. Ozdemir, M. PA, A. Pain, J. D. Pandian, P. R. Pant, C. Papachristou, E.-K. Park, J.-H. Park, C. D. Parry, M. Parsaeian, A. J. P. Caicedo, S. B. Patten, G. C. Patton, V. K. Paul, N. Pearce, J. M. Pedro, L. P. Stokic, D. M. Pereira, N. Perico, K. Pesudovs, M. Petzold, M. R. Phillips, F. B. Piel, J. D. Pillay, D. Plass, J. A. Platts-Mills, S. Polinder, C. A. Pope, S. Popova, R. G. Poulton, F. Pourmalek, D. Prabhakaran, M. Qorbani, J. Quame-Amaglo, D. A. Quistberg, A. Rafay, K. Rahimi, V. Rahimi-Movaghar, M. Rahman, M. H. U. Rahman, S. U. Rahman, R. K. Rai, Z. Rajavi, S. Rajsic, M. Raju, I. Rakovac, S. M. Rana, C. L. Ranabhat, T. Rangaswamy, P. Rao, S. R. Rao, A. H. Refaat, J. Rehm, M. B. Reitsma, G. Remuzzi, S. Resnikoff, A. L. Ribeiro, S. Ricci, M. J. R. Blancas, B. Roberts, A. Roca, D. Rojas-Rueda, L. Ronfani, G. Roshandel, D. Rothenbacher, A. Roy, N. K. Roy, G. M. Ruhago, R. Sagar, S. Saha, R. Sahathevan, M. M. Saleh, J. R. Sanabria, M. D. Sanchez-Niño, L. Sanchez-Riera, I. S. Santos, R. Sarmiento-Suarez, B. Sartorius, M. Satpathy, M. Savic, M. Sawhney, M. P. Schaub, M. I. Schmidt, I. J. C. Schneider, B. Schöttker, A. E. Schutte, D. C. Schwebel, S. Seedat, S. G. Sepanlou, E. E. Servan-Mori, K. A. Shackelford, G. Shaddick, A. Shaheen, S. Shahraz, M. A. Shaikh, M. Shakh-Nazarova, R. Sharma, J. She, S. Sheikhbahaei, J. Shen, Z. Shen, D. S. Shepard, K. N. Sheth, B. P. Shetty, P. Shi, K. Shibuya, M.-J. Shin, R. Shiri, I. Shiue, M. G. Shrime, I. D. Sigfusdottir, D. H. Silberberg, D. A. S. Silva, D. G. A. Silveira, J. I. Silverberg, E. P. Simard, A. Singh, G. M. Singh, J. A. Singh, O. P. Singh, P. K. Singh, V. Singh, S. Soneji, K. Søreide, J. B. Soriano, L. A. Sposato, C. T.

Sreeramareddy, V. Stathopoulou, D. J. Stein, M. B. Stein, S. Stranges, K. Stroumpoulis, B. F. Sunguya, P. Sur, S. Swaminathan, B. L. Sykes, C. E. I. Szoeke, R. Tabarés-Seisdedos, K. M. Tabb, K. Takahashi, J. S. Takala, R. T. Talongwa, N. Tandon, M. Tavakkoli, B. Taye, H. R. Taylor, B. J. Te Ao, B. A. Tedla, W. M. Tefera, M. Ten Have, A. S. Terkawi, F. H. Tesfay, G. A. Tessema, A. J. Thomson, A. L. Thorne-Lyman, A. G. Thrift, G. D. Thurston, T. Tillmann, D. L. Tirschwell, M. Tonelli, R. Topor-Madry, F. Topouzis, J. A. Towbin, J. Traebert, B. X. Tran, T. Truelsen, U. Trujillo, A. K. Tura, E. M. Tuzcu, U. S. Uchendu, K. N. Ukwaja, E. A. Undurraga, O. A. Uthman, R. Van Dingenen, A. van Donkelaar, T. Vasankari, A. M. N. Vasconcelos, N. Venketasubramanian, R. Vidavalur, L. Vijayakumar, S. Villalpando, F. S. Violante, V. V. Vlassov, J. A. Wagner, G. R. Wagner, M. T. Wallin, L. Wang, D. A. Watkins, S. Weichenthal, E. Weiderpass, R. G. Weintraub, A. Werdecker, R. Westerman, R. A. White, T. Wijeratne, J. D. Wilkinson, H. C. Williams, C. S. Wiysonge, S. M. Woldeyohannes, C. D. A. Wolfe, S. Won, J. Q. Wong, A. D. Woolf, D. Xavier, Q. Xiao, G. 
601

602

603

604

605

606

607

608

609

610

611

612

613

614

615

616

617

618

619

620

621

622

623

624

625

626

627

628

629

630

631

632

633

634

635

636

Xu, B. Yakob, A. Z. Yalew, L. L. Yan, Y. Yano, M. Yaseri, P. Ye, H. G. Yebyo, P. Yip, B. D. Yirsaw, N. Yonemoto, G. Yonga, M. Z. Younis, S. Yu, Z. Zaidi, M. E. S. Zaki, F. Zannad, D. E. Zavala, H. Zeeb, B. M. Zeleke, H. Zhang, S. Zodpey, D. Zonies, L. J. Zuhlke, T. Vos, A. D. Lopez, and C. J. L. Murray, "Global, regional, and national life expectancy, all-cause mortality, and cause-specific mortality for 249 causes of death, 1980-2015: a systematic analysis for the Global Burden of Disease Study 2015," Lancet, vol. 388, no. 10053, pp. 1459-1544, Oct. 2016.

[3] T. Vos, C. Allen, M. Arora, R. M. Barber, Z. A. Bhutta, A. Brown, A. Carter, D. C. Casey, F. J. Charlson, A. Z. Chen, M. Coggeshall, L. Cornaby, L. Dandona, D. J. Dicker, T. Dilegge, H. E. Erskine, A. J. Ferrari, C. Fitzmaurice, T. Fleming, M. H. Forouzanfar, N. Fullman, P. W. Gething, E. M. Goldberg, N. Graetz, J. A. Haagsma, S. I. Hay, C. O. Johnson, N. J. Kassebaum, T. Kawashima, L. Kemmer, I. A. Khalil, Y. Kinfu, H. H. Kyu, J. Leung, X. Liang, S. S. Lim, A. D. Lopez, R. Lozano, L. Marczak, G. A. Mensah, A. H. Mokdad, M. Naghavi, G. Nguyen, E. Nsoesie, H. Olsen, D. M. Pigott, C. Pinho, Z. Rankin, N. Reinig, J. A. Salomon, L. Sandar, A. Smith, J. Stanaway, C. Steiner, S. Teeple, B. A. Thomas, C. Troeger, J. A. Wagner, H. Wang, V. Wanga, H. A. Whiteford, L. Zoeckler, A. A. Abajobir, K. H. Abate, C. Abbafati, K. M. Abbas, F. Abd-Allah, B. Abraham, I. Abubakar, L. J. Abu-Raddad, N. M. E. Abu-Rmeileh, I. N. Ackerman, A. O. Adebiyi, Z. Ademi, A. K. Adou, K. A. Afanvi, E. E. Agardh, A. Agarwal, A. A. Kiadaliri, H. Ahmadieh, O. N. Ajala, R. O. Akinyemi, N. Akseer, Z. Al-Aly, K. Alam, N. K. M. Alam, S. F. Aldhahri, M. A. Alegretti, Z. A. Alemu, L. T. Alexander, S. Alhabib, R. Ali, A. Alkerwi, F. Alla, P. Allebeck, R. Al-Raddadi, U. Alsharif, K. A. Altirkawi, N. Alvis-Guzman, A. T. Amare, A. Amberbir, H. Amini, W. Ammar, S. M. Amrock, H. H. Andersen, G. M. Anderson, B. O. Anderson, C. A. T. Antonio, A. F. Aregay, J. Ärnlöv, A. Artaman, H. Asayesh, R. Assadi, S. Atique, E. F. G. A. Avokpaho, A. Awasthi, B. P. A. Quintanilla, P. Azzopardi, U. Bacha, A. Badawi, K. Balakrishnan, A. Banerjee, A. Barac, S. L. Barker-Collo, T. Bärnighausen, L. Barregard, L. H. Barrero, A. Basu, S. Bazargan-Hejazi, E. Beghi, B. Bell, M. L. Bell, D. A. Bennett, I. M. Bensenor, H. Benzian, A. Berhane, E. Bernabé, B. D. Betsu, A. S. Beyene, N. Bhala, S. Bhatt, S. Biadgilign, K. Bienhoff, B. Bikbov, S. Biryukov, D. Bisanzio, E. Bjertness, J. Blore, R. Borschmann, S. Boufous, M. Brainin, A. Brazinova, N. J. K. Breitborde, J. Brown, R. Buchbinder, G. C. Buckle, Z. A. Butt, B. Calabria, I. R. Campos-Nonato, J. C. Campuzano, H. Carabin, R. Cárdenas, D. O. Carpenter, J. J. Carrero, C. A. Castañeda-Orjuela, J. C. Rivas, F. Catalá-López, J.-C. Chang, P. P.-C. Chiang, C. E. Chibueze, V. H. Chisumpa, J.-Y. J. Choi, R. Chowdhury, H. Christensen, D. J. Christopher, L. G. Ciobanu, M. Cirillo, M. M. Coates, S. M. Colquhoun, C. Cooper, M. Cortinovis, J. A. Crump, S. A. Damtew, R. Dandona, F. Daoud, P. I. Dargan, J. das Neves, G. Davey, A. C. Davis, D. De Leo, L. Degenhardt, L. C. Del Gobbo, R. P. Dellavalle, K. Deribe, A. Deribew, S. Derrett, D. C. Des Jarlais, S. D. Dharmaratne, P. K. Dhillon, C. Diaz-Torné, E. L. Ding, T. R. Driscoll, L. Duan, M. Dubey, B. B. Duncan, H. Ebrahimi, R. G. Ellenbogen, I. Elyazar, M. Endres, A. Y. Endries, S. P. Ermakov, B. Eshrati, K. Estep, T. A. Farid, C. S. e S. Farinha, A. Faro, M. S. Farvid, F. Farzadfar, V. L. Feigin, D. T. Felson, S.-M. Fereshtehnejad, J. G. Fernandes, J. C. Fernandes, F. Fischer, J. R. A. Fitchett, K. Foreman, F. G. R. Fowkes, J. Fox, R. C. Franklin, J. Friedman, J. Frostad, T. Fürst, N. D. Futran, B. Gabbe, P. Ganguly, F. G. Gankpé, T. Gebre, T. T. Gebrehiwot, A. T. Gebremedhin, J. M. Geleijnse, B. D. Gessner, 
637

638

639

640

641

642

643

644

645

646

647

648

649

650

651

652

653

654

655

656

657

658

659

660

661

662

663

664

665

666

667

668

669

670

671

672

673

674

675

676

677

678

679

680

K. B. Gibney, I. A. M. Ginawi, A. Z. Giref, M. Giroud, M. D. Gishu, G. Giussani, E. Glaser, W. W. Godwin, H. Gomez-Dantes, P. Gona, A. Goodridge, S. V. Gopalani, C. C. Gotay, A. Goto, H. N. Gouda, R. Grainger, F. Greaves, F. Guillemin, Y. Guo, R. Gupta, R. Gupta, V. Gupta, R. A. Gutiérrez, D. Haile, A. D. Hailu, G. B. Hailu, Y. A. Halasa, R. R. Hamadeh, S. Hamidi, M. Hammami, J. Hancock, A. J. Handal, G. J. Hankey, Y. Hao, H. L. Harb, S. Harikrishnan, J. M. Haro, R. Havmoeller, R. J. Hay, I. B. Heredia-Pi, P. Heydarpour, H. W. Hoek, M. Horino, N. Horita, H. D. Hosgood, D. G. Hoy, A. S. Htet, H. Huang, J. J. Huang, C. Huynh, M. Iannarone, K. M. Iburg, K. Innos, M. Inoue, V. J. Iyer, K. H. Jacobsen, N. Jahanmehr, M. B. Jakovljevic, M. Javanbakht, S. P. Jayaraman, A. U. Jayatilleke, S. H. Jee, P. Jeemon, P. N. Jensen, Y. Jiang, T. Jibat, A. Jimenez-Corona, Y. Jin, J. B. Jonas, Z. Kabir, Y. Kalkonde, R. Kamal, H. Kan, A. Karch, C. K. Karema, C. Karimkhani, A. Kasaeian, A. Kaul, N. Kawakami, P. N. Keiyoro, A. H. Kemp, A. Keren, C. N. Kesavachandran, Y. S. Khader, A. R. Khan, E. A. Khan, Y.-H. Khang, S. Khera, T. A. M. Khoja, J. Khubchandani, C. Kieling, P. Kim, C. Kim, D. Kim, Y. J. Kim, N. Kissoon, L. D. Knibbs, A. K. Knudsen, Y. Kokubo, D. Kolte, J. A. Kopec, S. Kosen, G. A. Kotsakis, P. A. Koul, A. Koyanagi, M. Kravchenko, B. K. Defo, B. K. Bicer, A. A. Kudom, E. J. Kuipers, G. A. Kumar, M. Kutz, G. F. Kwan, A. Lal, R. Lalloo, T. Lallukka, H. Lam, J. O. Lam, S. M. Langan, A. Larsson, P. M. Lavados, J. L. Leasher, J. Leigh, R. Leung, M. Levi, Y. Li, Y. Li, J. Liang, S. Liu, Y. Liu, B. K. Lloyd, W. D. Lo, G. Logroscino, K. J. Looker, P. A. Lotufo, R. Lunevicius, R. A. Lyons, M. T. Mackay, M. Magdy, A. El Razek, M. Mahdavi, M. Majdan, A. Majeed, R. Malekzadeh, W. Marcenes, D. J. Margolis, J. Martinez-Raga, F. Masiye, J. Massano, S. T. McGarvey, J. J. McGrath, M. McKee, B. J. McMahon, P. A. Meaney, A. Mehari, F. Mejia-Rodriguez, A. B. Mekonnen, Y. A. Melaku, P. Memiah, Z. A. Memish, W. Mendoza, A. Meretoja, T. J. Meretoja, F. A. Mhimbira, A. Millear, T. R. Miller, E. J. Mills, M. Mirarefin, P. B. Mitchell, C. N. Mock, A. Mohammadi, S. Mohammed, L. Monasta, J. C. M. Hernandez, M. Montico, M. D. Mooney, M. MoradiLakeh, L. Morawska, U. O. Mueller, E. Mullany, J. E. Mumford, M. E. Murdoch, J. B. Nachega, G. Nagel, A. Naheed, L. Naldi, V. Nangia, J. N. Newton, M. Ng, F. N. Ngalesoni, Q. Le Nguyen, M. I. Nisar, P. M. N. Pete, J. M. Nolla, O. F. Norheim, R. E. Norman, B. Norrving, B. P. Nunes, F. A. Ogbo, I.-H. Oh, T. Ohkubo, P. R. Olivares, B. O. Olusanya, J. O. Olusanya, A. Ortiz, M. Osman, E. Ota, M. PA, E.-K. Park, M. Parsaeian, V. M. de Azeredo Passos, A. J. P. Caicedo, S. B. Patten, G. C. Patton, D. M. Pereira, R. Perez-Padilla, N. Perico, K. Pesudovs, M. Petzold, M. R. Phillips, F. B. Piel, J. D. Pillay, F. Pishgar, D. Plass, J. A. Platts-Mills, S. Polinder, C. D. Pond, S. Popova, R. G. Poulton, F. Pourmalek, D. Prabhakaran, N. M. Prasad, M. Qorbani, R. H. S. Rabiee, A. Radfar, A. Rafay, K. Rahimi, V. Rahimi-Movaghar, M. Rahman, M. H. U. Rahman, S. U. Rahman, R. K. Rai, S. Rajsic, U. Ram, P. Rao, A. H. Refaat, M. B. Reitsma, G. Remuzzi, S. Resnikoff, A. Reynolds, A. L. Ribeiro, M. J. R. Blancas, H. S. Roba, D. Rojas-Rueda, L. Ronfani, G. Roshandel, G. A. Roth, D. Rothenbacher, A. Roy, R. Sagar, R. Sahathevan, J. R. Sanabria, M. D. Sanchez-Niño, I. S. Santos, J. V. Santos, R. Sarmiento-Suarez, B. Sartorius, M. Satpathy, M. Savic, M. Sawhney, M. P. Schaub, M. I. Schmidt, I. J. C. Schneider, B. Schöttker, D. C. Schwebel, J. G. Scott, S. Seedat, S. G. Sepanlou, E. E. Servan-Mori, K. A. Shackelford, A. Shaheen, M. A. Shaikh, R. Sharma, U. Sharma, J. Shen, D. S. Shepard, K. N. Sheth, K. Shibuya, M.-J. Shin, R. Shiri, I. Shiue, M. G. Shrime, I. D. Sigfusdottir, D. A. S. Silva, D. G. A. Silveira, A. Singh, J. A. Singh, O. P. Singh, P. K. Singh, A. Sivonda, V. Skirbekk, J. C. Skogen, A. Sligar, K. Sliwa, 
681

682

683

684

685

686

687

688

689

690

691

692

693

694

695

696

697

698

699

700

701

702

703

704

705

706

707

708

709

710

711

712

713

714

715

716

717

718

719

720

M. Soljak, K. Søreide, R. J. D. Sorensen, J. B. Soriano, L. A. Sposato, C. T. Sreeramareddy, V. Stathopoulou, N. Steel, D. J. Stein, T. J. Steiner, S. Steinke, L. Stovner, K. Stroumpoulis, B. F. Sunguya, P. Sur, S. Swaminathan, B. L. Sykes, C. E. I. Szoeke, R. Tabarés-Seisdedos, J. S. Takala, N. Tandon, D. Tanne, M. Tavakkoli, B. Taye, H. R. Taylor, B. J. Te Ao, B. A. Tedla, A. S. Terkawi, A. J. Thomson, A. L. Thorne-Lyman, A. G. Thrift, G. D. Thurston, R. Tobe-Gai, M. Tonelli, R. Topor-Madry, F. Topouzis, B. X. Tran, T. Truelsen, Z. T. Dimbuene, M. Tsilimbaris, A. K. Tura, E. M. Tuzcu, S. Tyrovolas, K. N. Ukwaja, E. A. Undurraga, C. J. Uneke, O. A. Uthman, C. H. van Gool, Y. Y. Varakin, T. Vasankari, N. Venketasubramanian, R. K. Verma, F. S. Violante, S. K. Vladimirov, V. V. Vlassov, S. E. Vollset, G. R. Wagner, S. G. Waller, L. Wang, D. A. Watkins, S. Weichenthal, E. Weiderpass, R. G. Weintraub, A. Werdecker, R. Westerman, R. A. White, H. C. Williams, C. S. Wiysonge, C. D. A. Wolfe, S. Won, R. Woodbrook, M. Wubshet, D. Xavier, G. Xu, A. K. Yadav, L. L. Yan, Y. Yano, M. Yaseri, P. Ye, H. G. Yebyo, P. Yip, N. Yonemoto, S.-J. Yoon, M. Z. Younis, C. Yu, Z. Zaidi, M. E. S. Zaki, H. Zeeb, M. Zhou, S. Zodpey, L. J. Zuhlke, and C. J. L. Murray, "Global, regional, and national incidence, prevalence, and years lived with disability for 310 diseases and injuries, 1990-2015: a systematic analysis for the Global Burden of Disease Study 2015," Lancet, vol. 388, no. 10053, pp. 1545-1602, Oct. 2016.

[4] E. Papaleo, L. Zollo, N. Garcia-Aracil, F. J. Badesa, R. Morales, S. Mazzoleni, S. Sterzi, and E. Guglielmelli, "Upper-limb kinematic reconstruction during stroke robot-aided therapy," Med. Biol. Eng. Comput., vol. 53, no. 9, pp. 815-828, Sep. 2015.

[5] K. H. Cho and W.-K. Song, "Robot-Assisted Reach Training for Improving Upper Extremity Function of Chronic Stroke," Tohoku J. Exp. Med., vol. 237, no. 2, pp. 149-155, 2015.

[6] R. Colombo, I. Sterpi, A. Mazzone, C. Delconte, and F. Pisano, "Robot-aided neurorehabilitation in sub-acute and chronic stroke: Does spontaneous recovery have a limited impact on outcome?," NeuroRehabilitation, vol. 33, no. 4, pp. 621-629, Jan. 2013.

[7] H. A. Rahman, K. K. Xiang, Y. C. Fai, E. S. L. Ming, and A. L. Narayanan, "Robotic Assessment Modules for Upper Limb Stroke Assessment: Preliminary Study," J. Med. Imaging Heal. Informatics, vol. 6, no. 1, pp. 157-162, Feb. 2016.

[8] M. Stefano, C. Andrea, R. Giulio, and A. Mario, "Robotic-Assisted Rehabilitation of the Upper Limb After Acute Stroke," Arch. Phys. Med. Rehabil., vol. 88, no. 2, pp. 142-149, Feb. 2007.

[9] V. Squeri, A. B.-... R. (ICORR), undefined 2011, and undefined 2011, "Adaptive regulation of assistance 'as needed'in robot-assisted motor skill learning and neuro-rehabilitation," ieeexplore.ieee.org.

[10] D. J. Reinkensmeyer, "How to retrain movement after neurologic injury: a computational rationale for incorporating robot (or therapist) assistance," in Proceedings of the 25th Annual International Conference of the IEEE Engineering in Medicine and Biology Society (IEEE Cat. No.03CH37439), pp. 1479-1482.

[11] K. J. Wisneski and M. J. Johnson, "Quantifying kinematics of purposeful movements to 
721

722

723

724

725

726

727

728

729

730

731

732

733

734

735

736

737

738

739

740

741

742

743

744

745

746

747

748

749

750

751

752

753

754

755

756

757

758

real, imagined, or absent functional objects: Implications for modelling trajectories for robot-assisted ADL tasks**," J. Neuroeng. Rehabil., vol. 4, no. 1, p. 7, Mar. 2007.

[12] L. Kahn, P. Lum, W. Rymer, and D. Reinkensmeyer, "Robot-assisted movement training for the stroke-impaired arm: Does it matter what the robot does?," 2014.

[13] D. L. Turner, A. Ramos-Murguialday, N. Birbaumer, U. Hoffmann, and A. Luft, "Neurophysiology of robot-mediated training and therapy: a perspective for future use in clinical populations.," Front. Neurol., vol. 4, p. 184, Nov. 2013.

[14] N. Hogan, H. I. Krebs, J. Charnnarong, P. Srikrishna, and A. Sharon, "MIT-MANUS: a workstation for manual therapy and training. I," in [1992] Proceedings IEEE International Workshop on Robot and Human Communication, pp. 161-165.

[15] N. Hogan, H. I. Krebs, J. Charnnarong, SrikrishnaP, and A. Sharon, "MIT-MANUS: a workstation for manual therapy and training II," in Applications in Optical Science and Engineering, 1993, vol. 1833, pp. 28-34.

[16] "Armeo ${ }^{\circledR}$ Power - Hocoma." [Online]. Available: https://www.hocoma.com/us/solutions/armeo-power/. [Accessed: 18-Oct-2017].

[17] M. Mihelj, T. Nef, and R. Riener, "ARMin - Toward a six DoF upper limb rehabilitation robot," in The First IEEE/RAS-EMBS International Conference on Biomedical Robotics and Biomechatronics, 2006. BioRob 2006., pp. 1154-1159.

[18] T. Nef, M. Mihelj, G. Colombo, and R. Riener, "ARMin - robot for rehabilitation of the upper extremities," in Proceedings 2006 IEEE International Conference on Robotics and Automation, 2006. ICRA 2006., pp. 3152-3157.

[19] R. S. Calabrò, M. Russo, A. Naro, D. Milardi, T. Balletta, A. Leo, S. Filoni, and P. Bramanti, "Who May Benefit From Armeo Power Treatment? A Neurophysiological Approach to Predict Neurorehabilitation Outcomes," PM\&R, vol. 8, pp. 971-978, 2016.

[20] A. Panarese, E. Pirondini, P. Tropea, B. Cesqui, F. Posteraro, and S. Micera, "Model-based variables for the kinematic assessment of upper-extremity impairments in post-stroke patients," J. Neuroeng. Rehabil., vol. 13, no. 1, p. 81, Dec. 2016.

[21] J. Stein, "Motor Recovery Strategies After Stroke," Top. Stroke Rehabil., vol. 11, no. 2, pp. 12-22, Apr. 2004.

[22] P. S. Norouzi-Gheidari, Nahid Archambault and J. Fung, "Effects of robot-assisted therapy on stroke rehabilitation in upper limbs: Systematic review and meta-analysis of the literature - ProQuest," J. Rehabil. Res. Dev., vol. 49, no. 4, pp. 479-96, 2012.

[23] G. B. Prange, M. J. A. Jannink, C. G. M. Groothuis-Oudshoorn, H. J. Hermens, and M. J. IJzerman, "Systematic review of the effect of robot-aided therapy on recovery of the hemiparetic arm after stroke - ProQuest," J. Rehabil. Res. Dev., vol. 43, no. 2, pp. 171-84, 2006.

[24] P. H. McCrea, J. J. Eng, and A. J. Hodgson, "Biomechanics of reaching: clinical implications for individuals with acquired brain injury," Disabil. Rehabil., vol. 24, no. 10, pp. 534-541, 
759

760

761

762

763

764

765

766

767

768

769

770

771

772

773

774

775

776

777

778

779

780

781

782

783

784

785

786

787

788

789

790

791

792

793

794

795

796

Jan. 2002.

[25] B. Rohrer, S. Fasoli, and H. Krebs, "Movement smoothness changes during stroke recovery," J. ..., 2002.

[26] C. Bosecker, L. Dipietro, B. Volpe, and H. I. Krebs, "Kinematic Robot-Based Evaluation Scales and Clinical Counterparts to Measure Upper Limb Motor Performance in Patients With Chronic Stroke," Neurorehabil. Neural Repair, vol. 24, no. 1, pp. 62-69.

[27] J. Van Kordelaar, E. Van Wegen, and G. Kwakkel, "Impact of Time on Quality of Motor Control of the Paretic Upper Limb After Stroke," 2014.

[28] J. van Kordelaar, E. van Wegen, and G. Kwakkel, "Impact of Time on Quality of Motor Control of the Paretic Upper Limb After Stroke," Arch. Phys. Med. Rehabil., vol. 95, no. 2, pp. 338-344, Feb. 2014.

[29] M. Caimmi, S. Carda, C. Giovanzana, S. Maini, A. M. Sabatini, N. Smania, and F. Molteni, "Using Kinematic Analysis to Evaluate Constraint-Induced Movement Therapy in Chronic Stroke Patients."

[30] W. Liao, C. Wu, Y. Hsieh, K. Lin, and W. Chang, "Effects of robot-assisted upper limb rehabilitation on daily function and real-world arm activity in patients with chronic stroke: a randomized controlled trial," Clin. Rehabil., vol. 26, no. 2, pp. 111-120, Feb. 2012.

[31] V. M. Parker, D. T. Wade, and R. L. Hewer, "Loss of arm function after stroke: measurement, frequency, and recovery," Int. Rehabil. Med., vol. 8, no. 2, pp. 69-73, Jan. 1986.

[32] A. Heller, D. T. Wade, V. A. Wood, A. Sunderland, R. L. Hewer, and E. Ward, "Arm function after stroke: measurement and recovery over the first three months.," J. Neurol. Neurosurg. Psychiatry, vol. 50, no. 6, pp. 714-9, Jun. 1987.

[33] K. J. Sullivan, J. K. Tilson, S. Y. Cen, D. K. Rose, J. Hershberg, A. Correa, J. Gallichio, M. McLeod, C. Moore, S. S. Wu, and P. W. Duncan, "Fugl-Meyer assessment of sensorimotor function after stroke: standardized training procedure for clinical practice and clinical trials.," Stroke, vol. 42, no. 2, pp. 427-32, Feb. 2011.

[34] "SMART-DX | Motion Capture Systems | BTS Bioengineering." [Online]. Available: http://www.btsbioengineering.com/products/smart-dx/?gclid=EAlalQobChMItMalNr61gIVExMbChORQQqZEAAYASAAEgJ9wPD_BwE. [Accessed: 18-Oct-2017].

[35] G. Rab, K. Petuskey, and A. Bagley, "A method for determination of upper extremity kinematics," Gait Posture, vol. 15, no. 2, pp. 113-119, Apr. 2002.

[36] M. Alt Murphy, C. Willén, and K. S. Sunnerhagen, "Movement Kinematics During a Drinking Task Are Associated With the Activity Capacity Level After Stroke," Neurorehabil. Neural Repair, vol. 26, no. 9, pp. 1106-1115, Nov. 2012.

[37] M. Alt Murphy and Margit, Development and validation of upper extremity kinematic movement analysis for people with stroke reaching and drinking from a glass. Institute of 
797

798

799

800

801

802

803

804

805

806

807

808

809

810

811

812

813

814

815

816

817

818

819

820

821

822

823

824

825

826

827

828

829

830

831

832

833

834

Neuroscience and Physiology. Department of Clinical Neuroscience and Rehabilitation, University of Gothenburg, 2013.

[38] A. Frisoli, C. Procopio, C. Chisari, I. Creatini, L. Bonfiglio, M. Bergamasco, B. Rossi, and M. Carboncini, "Positive effects of robotic exoskeleton training of upper limb reaching movements after stroke," J. Neuroeng. Rehabil., vol. 9, no. 1, p. 36, Jun. 2012.

[39] C. G. Burgar, P. S. Lum, A. M. E. Scremin, S. L. Garber, H. F. M. Van der Loos, D. Kenney, and $P$. Shor, "Robot-assisted upper-limb therapy in acute rehabilitation setting following stroke: Department of Veterans Affairs multisite clinical trial.," J. Rehabil. Res. Dev., vol. 48, no. 4, pp. 445-58, 2011.

[40] S. K. Subramanian, J. Yamanaka, G. Chilingaryan, and M. F. Levin, "Validity of Movement Pattern Kinematics as Measures of Arm Motor Impairment Poststroke," Stroke, vol. 41, no. 10, pp. 2303-2308, Oct. 2010.

[41] M. Coscia, V. C. Cheung, P. Tropea, A. Koenig, V. Monaco, C. Bennis, S. Micera, and P. Bonato, "The effect of arm weight support on upper limb muscle synergies during reaching movements," J. Neuroeng. Rehabil., vol. 11, no. 1, p. 22, Mar. 2014.

[42] M. Bartolo, A. M. De Nunzio, F. Sebastiano, F. Spicciato, P. Tortola, J. Nilsson, and F. Pierelli, "Arm weight support training improves functional motor outcome and movement smoothness after stroke.," Funct. Neurol., vol. 29, no. 1, pp. 15-21.

[43] C. Rigoldi, E. Molteni, C. Rozbaczylo, M. Morante, G. Albertini, A. M. Bianchi, and M. Galli, "Movement analysis and EEG recordings in children with hemiplegic cerebral palsy," Exp. Brain Res., vol. 223, no. 4, pp. 517-524, Dec. 2012.

[44] F. Menegoni, E. Milano, C. Trotti, M. Galli, M. Bigoni, S. Baudo, and A. Mauro, "Quantitative evaluation of functional limitation of upper limb movements in subjects affected by ataxia," Eur. J. Neurol., vol. 16, no. 2, pp. 232-239, Feb. 2009.

[45] J. M. Bland and D. G. Altman, "One and two sided tests of significance.," BMJ, vol. 309, no. 6949, p. 248, Jul. 1994.

[46] R. Colombo, F. Pisano, S. Micera, A. Mazzone, C. Delconte, M. C. Carrozza, P. Dario, and G. Minuco, "Robotic Techniques for Upper Limb Evaluation and Rehabilitation of Stroke Patients," IEEE Trans. Neural Syst. Rehabil. Eng., vol. 13, no. 3, pp. 311-324, Sep. 2005.

[47] S. Balasubramanian, A. Melendez-Calderon, A. Roby-Brami, and E. Burdet, "On the analysis of movement smoothness," J. Neuroeng. Rehabil., vol. 12, no. 1, p. 112, Dec. 2015.

[48] V. Do Tran, P. Dario, and S. Mazzoleni, "Kinematic measures for upper limb robotassisted therapy following stroke and correlations with clinical outcome measures: A review.," Med. Eng. Phys., vol. 53, pp. 13-31, Mar. 2018.

[49] N. Hogan and D. Sternad, "Sensitivity of Smoothness Measures to Movement Duration, Amplitude, and Arrests," J. Mot. Behav., vol. 41, no. 6, pp. 529-534, Nov. 2009.

[50] M. A. Murphy, C. Willén, and K. S. Sunnerhagen, “Kinematic Variables Quantifying Upper- 
835 Extremity Performance After Stroke During Reaching and Drinking From a Glass,"

836

837

838

839

840

841

842

843

844

845

846

847

848

849

850

851

852

853

854

855

856
Neurorehabil. Neural Repair, vol. 25, no. 1, pp. 71-80.

[51] A. C. Lo, P. Guarino, H. I. Krebs, B. T. Volpe, C. T. Bever, P. W. Duncan, R. J. Ringer, T. H. Wagner, L. G. Richards, D. M. Bravata, J. K. Haselkorn, G. F. Wittenberg, D. G. Federman, B. H. Corn, A. D. Maffucci, and P. Peduzzi, "Multicenter randomized trial of robot-assisted rehabilitation for chronic stroke: methods and entry characteristics for VA ROBOTICS.," Neurorehabil. Neural Repair, vol. 23, no. 8, pp. 775-83, Oct. 2009.

[52] G. Kwakkel, R. C. Wagenaar, T. W. Koelman, G. J. Lankhorst, and J. C. Koetsier, "Effects of intensity of rehabilitation after stroke. A research synthesis.," Stroke, vol. 28, no. 8, pp. 1550-6, Aug. 1997.

[53] C. Duret and E. Hutin, "Effects of prolonged robot-assisted training on upper limb motor recovery in subacute stroke.," NeuroRehabilitation, vol. 33, no. 1, pp. 41-8, 2013.

[54] M. C. Cirstea and M. F. Levin, "Compensatory strategies for reaching in stroke.," Brain, vol. 123 ( Pt 5, pp. 940-53, May 2000.

[55] N. Nordin, S. Xie, and B. Wünsche, "Assessment of movement quality in robot- assisted upper limb rehabilitation after stroke: a review," J. Neuroeng. Rehabil., vol. 11, no. 1, p. 137, Sep. 2014.

[56] M. Caimmi, S. Carda, C. Giovanzana, E. S. Maini, A. M. Sabatini, N. Smania, and F. Molteni, "Using Kinematic Analysis to Evaluate Constraint-Induced Movement Therapy in Chronic Stroke Patients," Neurorehabil. Neural Repair, vol. 22, no. 1, pp. 31-39, Jan. 2008. 


\section{Figure 1}

The Hocoma Armeo ${ }^{\circledR}$ Power

A six degrees of freedom (DoFs) exoskeleton: three DoFs for the shoulder, one for the elbow flexion, one for the forearm supination, and one for the wrist flexion. Each joint is powered by a motor and equipped with two angle sensors (Photo: E F Russo). 


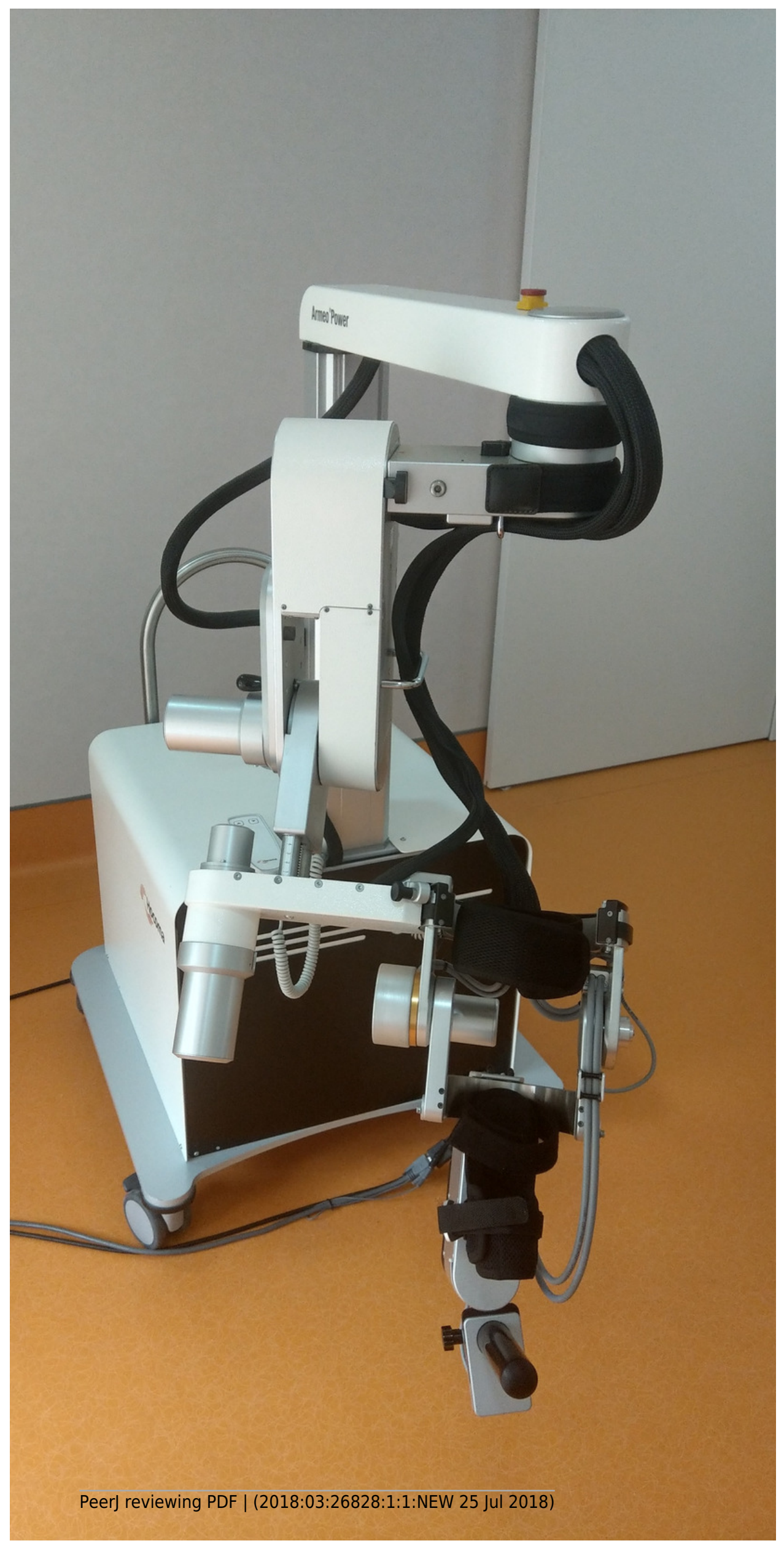


Figure 2

Subject performing the reaching task

Reflective markers are placed on the body according to the kinematic model adopted. A reflective marker is also placed on the target, installed on a rod in front of the subject, at the height of the shoulders. The rod was moved at every trial to align the target with the shoulder performing the reaching task (Photo: E F Russo). 


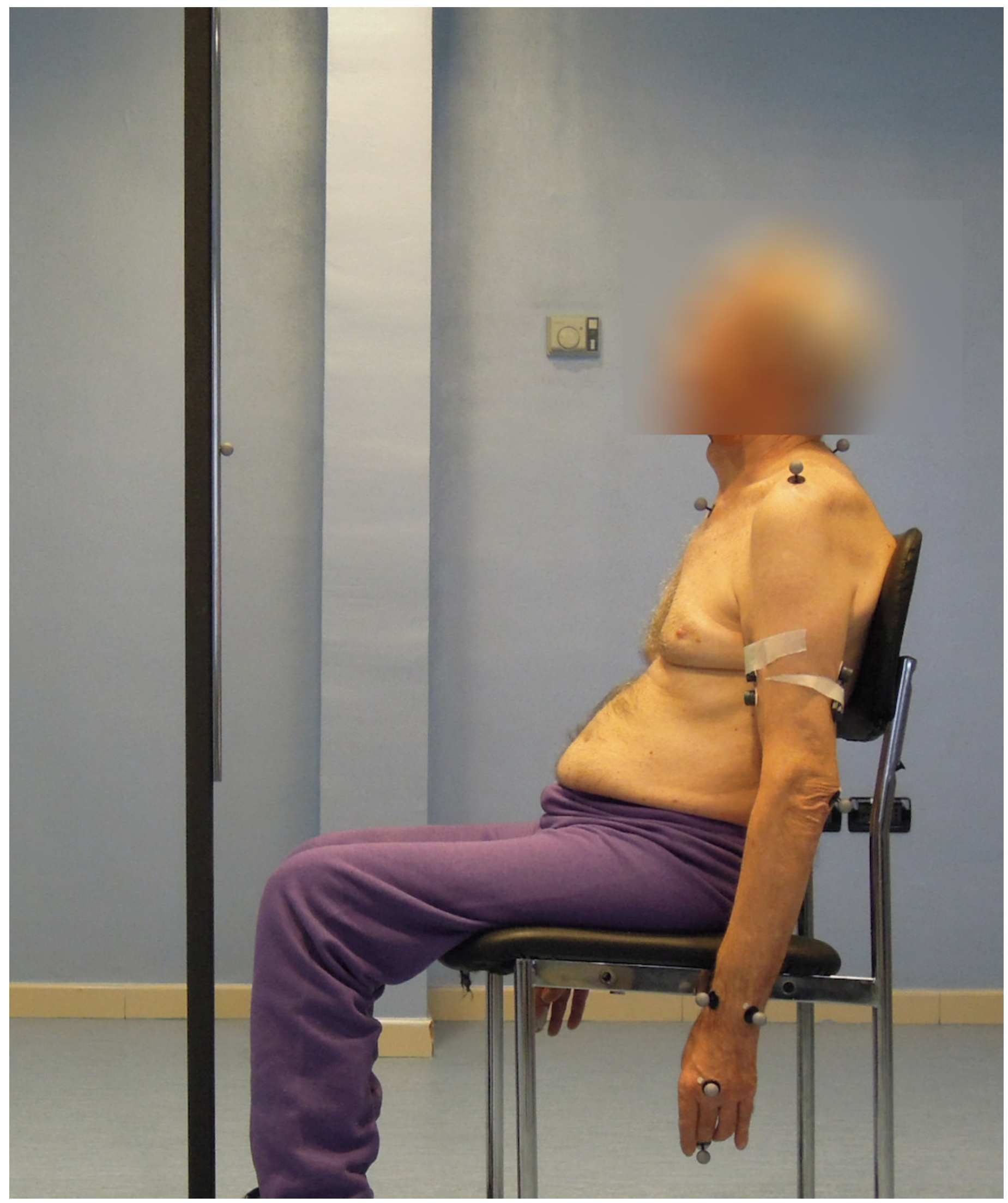


Figure 3

Kinematic model for reflective marker placement adopted in this study

12 markers (14 mm diameter) are placed over prominent bony landmarks of the upper extremity, easily identifiable and reproducible, where subcutaneous tissue is thin, minimizing soft tissue artifact due to marker movement with respect to bone.

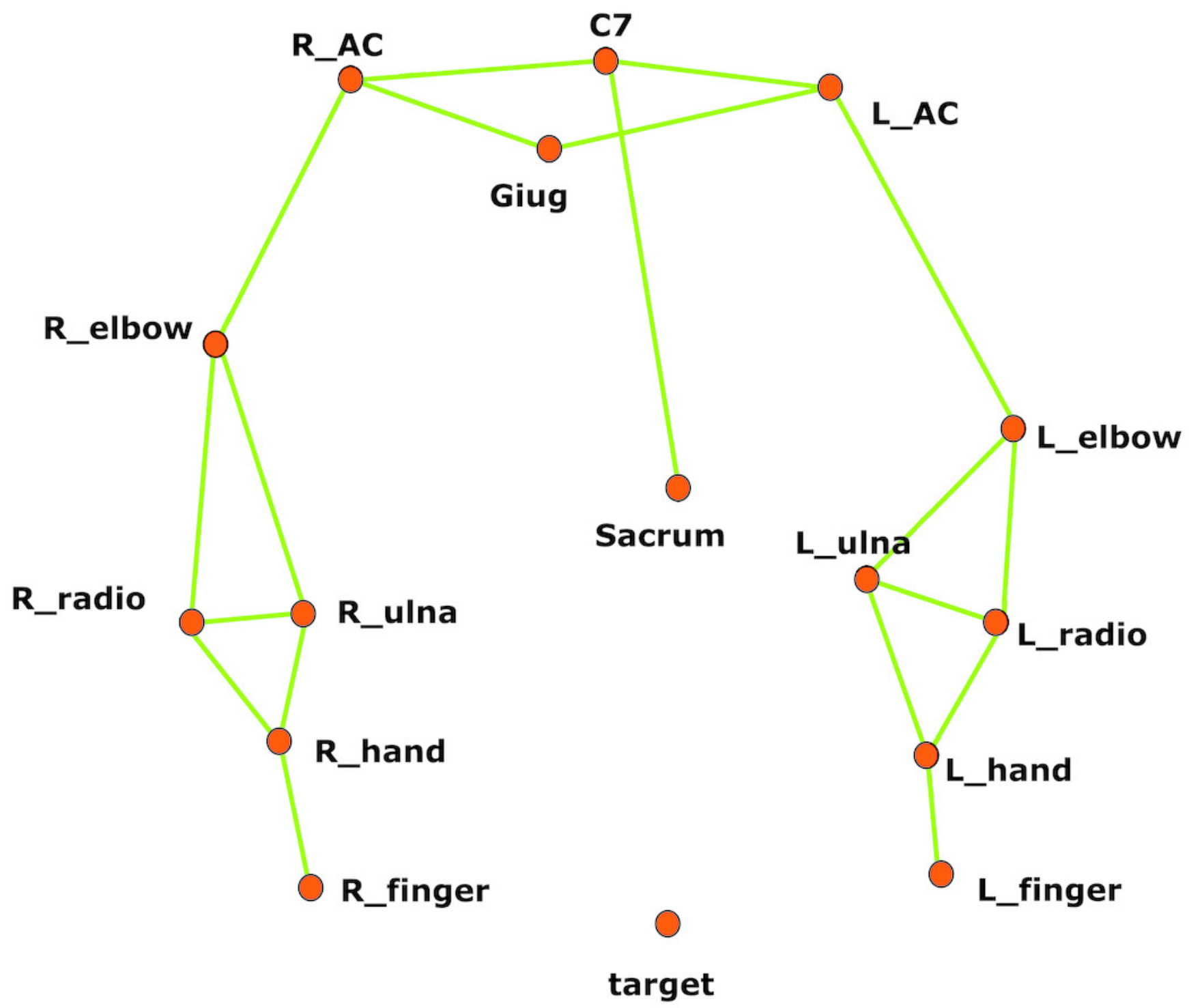




\section{Figure 4}

\section{Example of hand trajectories}

Hand trajectories (in blue) during the reaching task, with respect to the shortest path (in red). (A): Reaching trajectory of the paretic arm before the treatment. (B): Reaching trajectory of the paretic arm after the treatment. (C): Trajectory of the unaffected arm.

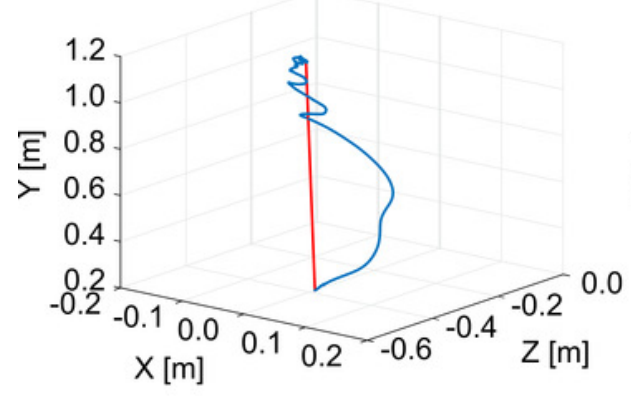

A

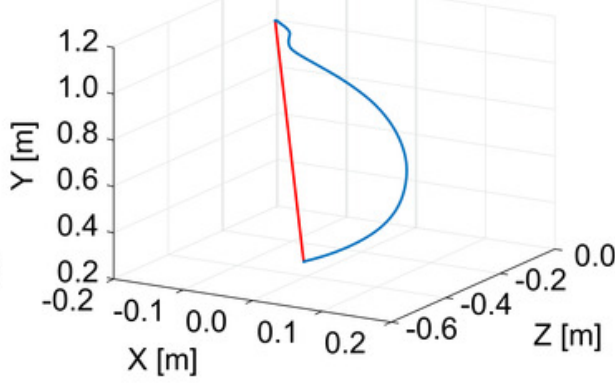

B

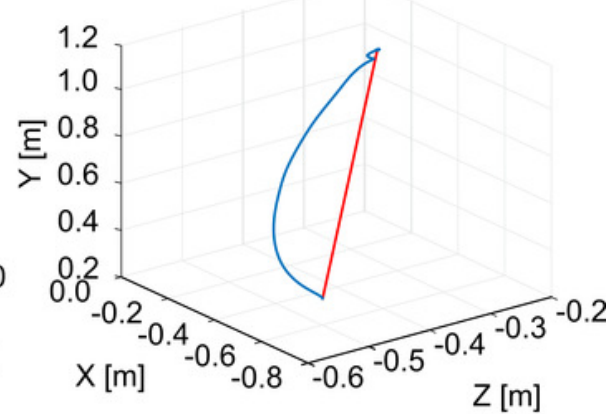

C 


\section{Figure 5}

Mean value of the $\mathrm{N}$ of hand trajectories for the ten patients across the different trials

The bars represent the standard deviation ( \pm ). For each patient, values obtained with the affected arm before the treatment (green) are compared to those obtained with the same arm after the treatment (blue). Values obtained with the unaffected arm are also reported for visual comparison (yellow).

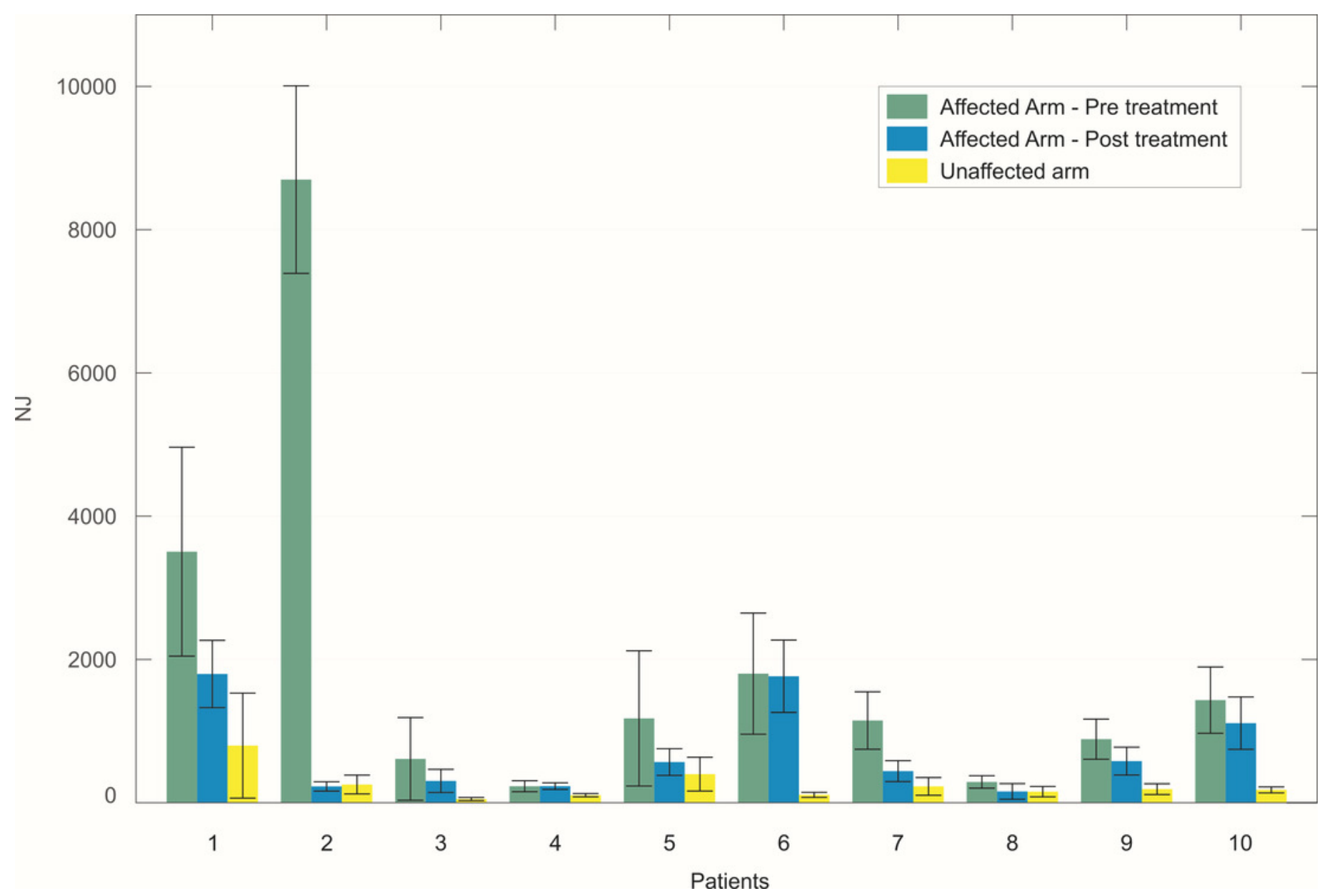




\section{Figure 6}

Mean values of the six kinematic indices calculated across all the patients

Error bars represent the standard deviation $( \pm)$. For each index, mean values obtained with the affected arm before the treatment are depicted in green. Values obtained with the same arm after the treatment are reported in blue. Statistical significance between the two conditions are starred. For visual comparison, values obtained with the non affected arm are also reported in yellow.
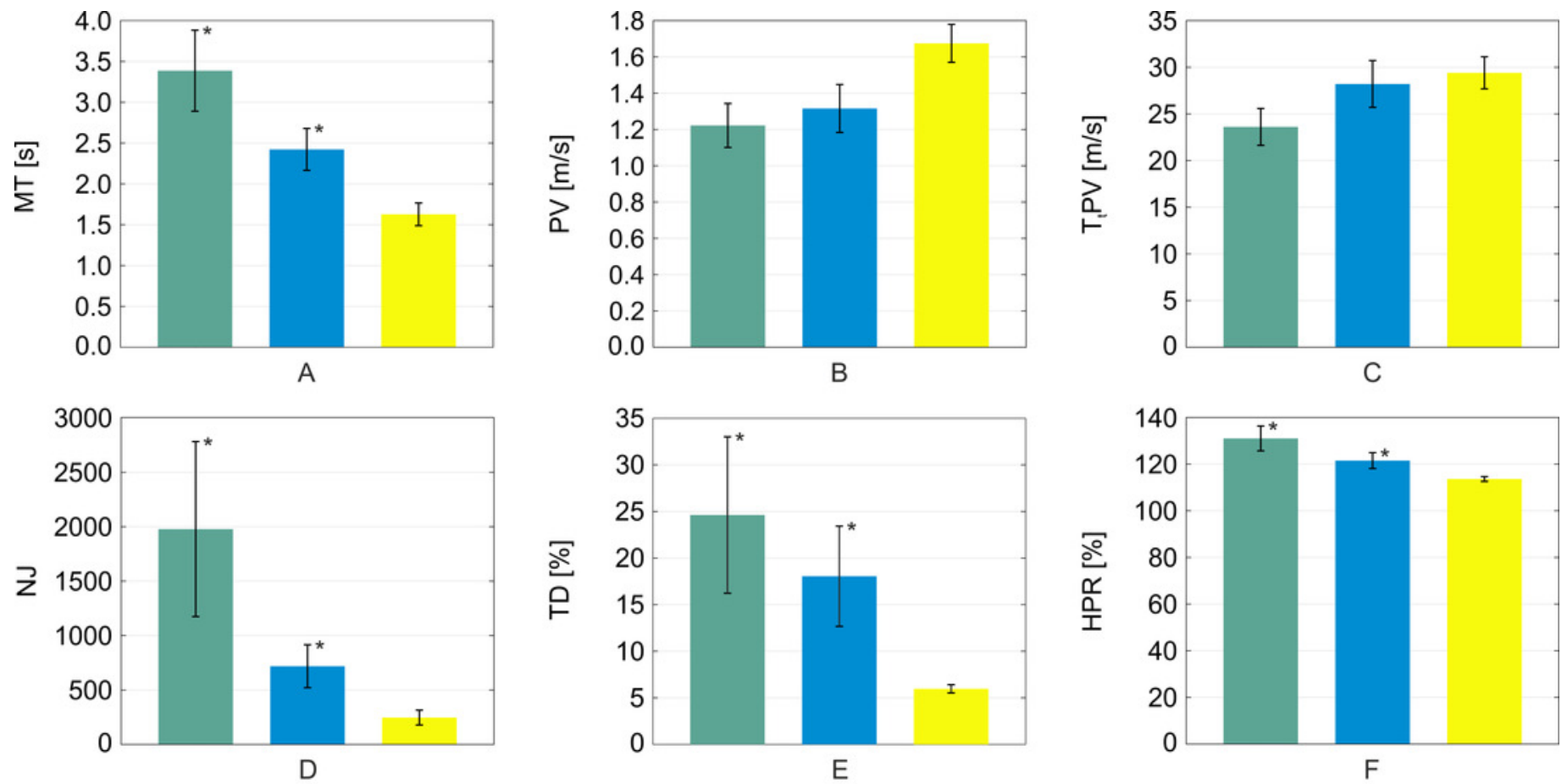
Table $\mathbf{1}$ (on next page)

Clinical data of the patients' population 


\begin{tabular}{lcccc}
\hline Patient & Gender & Age & Affected side & Months after event \\
\hline 1 & M & 66 & Left & 5 \\
2 & F & 56 & Right & 2 \\
3 & M & 40 & Left & 5 \\
4 & M & 74 & Left & 5 \\
5 & M & 73 & Right & 4 \\
6 & M & 54 & Right & 4 \\
7 & M & 65 & Left & 2 \\
8 & M & 21 & Right & 2 \\
9 & M & 69 & Right & 6 \\
10 & F & 83 & Left & 5 \\
\hline
\end{tabular}

1 


\section{Table 2 (on next page)}

Spearman correlation coefficients and significance level (in brackets) between the 4 clinical scales score and kinematic parameters, evaluated post-treatment 


\begin{tabular}{lccc}
\hline Scale & Pre-treatment & Post-treatment & $\boldsymbol{p}$ value \\
\hline FIM & $78.5 \pm 19.1$ & $98.7 \pm 13.6$ & 0.005 \\
BI & $52.5 \pm 21.1$ & $75.5 \pm 14.0$ & 0.005 \\
FAT & $1.5 \pm 1.4$ & $4.2 \pm 1.1$ & 0.005 \\
FMA & $32.6 \pm 13.9$ & $45 \pm 10.7$ & 0.005 \\
\hline
\end{tabular}

1 


\section{Table 3(on next page)}

Pre-treatment and post-treatment values (mean \pm standard deviation) of clinical scales 


\begin{tabular}{ccccccc}
\hline \multirow{5}{*}{ Scale } & MT & PV & $T_{T} P V$ & NJ & TD & HPR \\
& & & & & & \\
\hline \multirow{2}{*}{ FM } & -0.164 & 0.024 & 0.359 & -0.207 & -0.140 & -0.049 \\
& $(0.650)$ & $(0.947)$ & $(0.309)$ & $(0.567)$ & $(0.699)$ & $(0.894)$ \\
& -0.470 & 0.384 & -0.049 & -0.396 & -0.511 & 0.024 \\
BI & $(0.171)$ & $(0.273)$ & $(0.894)$ & $(0.257)$ & $(0.131)$ & $(0.947)$ \\
& -0.192 & -0.096 & 0.528 & -0.329 & 0.364 & -0.624 \\
FAT & $(0.595)$ & $(0.792)$ & $(0.117)$ & $(0.353)$ & $(0.301)$ & 0.054 \\
& -0.036 & -0.120 & 0.164 & 0 & 0.152 & -0.426 \\
FMA & $(0.920)$ & $(0.973)$ & $(0.650)$ & 1 & $(0.674)$ & $(0.220)$ \\
\hline
\end{tabular}

1 